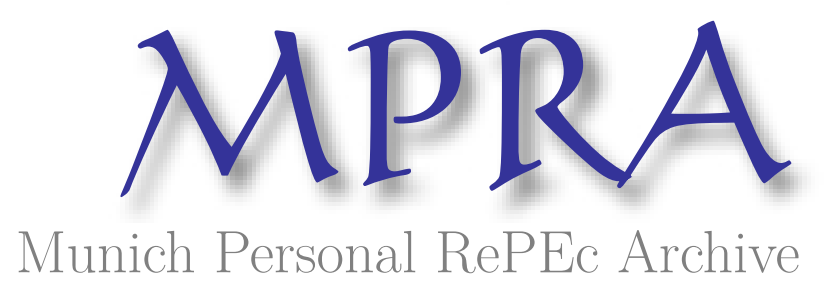

\title{
Network Structure and Consolidation in the U.S. Airline Industry, 1990-2015
}

Ciliberto, Federico and Cook, Emily and Williams, Jonathan

University of Virginia, University of Virginia, UNC Chapel Hill

2017

Online at https://mpra.ub.uni-muenchen.de/83885/

MPRA Paper No. 83885, posted 11 Jan 2018 15:19 UTC 


\title{
Network Structure and Consolidation in the U.S. Airline Industry, 1990-2015
}

\author{
Federico Ciliberto* $\quad$ Emily E. Cook ${ }^{\dagger} \quad$ Jonathan W. Williams ${ }^{\ddagger}$ \\ UVA \\ UVA \\ UNC - Chapel Hill
}

August 21, 2017

\begin{abstract}
We study the effect of consolidation on airline network connectivity using three measures of centrality from graph theory: Degree, Closeness, and Betweenness. Changes in these measures from 1990 to 2015 imply: i) the average airport services a greater proportion of possible routes, ii) the average origin airport is fewer stops away from any given destination, and iii) the average hub is less often along the shortest route between two other airports. Yet, we find the trend toward greater connectivity in the national network structure is largely unaffected by consolidation, in the form of mergers and codeshare agreements, during this period.
\end{abstract}

${ }^{*}$ Department of Economics, University of Virginia, ciliberto@virginia.edu. Federico Ciliberto acknowledges the Quantitative Collaborative at the University of Virginia for financial support.

${ }^{\dagger}$ Department of Economics, University of Virginia, eec3ah@virginia.edu.

${ }^{\ddagger}$ Department of Economics, University of North Carolina, Chapel Hill, jonwms@unc.edu 


\section{Introduction}

Forty years after its deregulation, the airline industry continues to be the focus of research, antitrust cases, and public policy debates. For the most part this is because the US airline industry continues to evolve in ways that are complex and consequential for many people. In this paper we contribute to the evolving debate by examining how mergers and alliances have shaped the entire industry's U.S. network. Our objective is to shed light on important trends in the network structure, which have direct consequences for service convenience and quality experienced by consumers.

In 1993 there were eight fully independent legacy carriers (American, America West, Continental, Delta, Northwest, Trans World Airlines, United, US Airways), some very localized airlines, such as Alaska and Hawaiian, and few small low cost carriers. The legacy carriers served all the largest cities of the U.S., but they operated mostly at the regional level. ${ }^{1}$ A wave of consolidations began when Continental and Northwest signed an agreement to codeshare flights in 1998. ${ }^{2}$ This agreement was followed in 2001 by the acquisition of Trans World Airlines by American and in early 2003, by the codeshare agreement between United and US Airways and the inclusion of Delta in the codeshare agreement with Continental and Northwest. Finally, in 2005, America West acquired US Airways. Another wave of consolidation started with Northwest and Delta merging in 2008, and was followed by United and Continental in 2010, Southwest and AirTran in 2011, and American and US Airways in $2013 .{ }^{3}$ As a result, today there are three legacy carriers (American, Delta, and United) and Southwest with fully national networks; Alaska and JetBlue with regional networks (the former with a strong presence on the West coast and the latter with a strong presence on

\footnotetext{
${ }^{1}$ For example, US Airways had a strong presence in the East coast, while United had a strong presence in the West coast.

${ }^{2}$ America West and Continental had a code-sharing agreement from 1994 to 2002. The agreement was signed as part of the restructuring plan of America West, while it was under Chapter 11 protection from 1991 to 1994. Northwest and Alaska had a codesharing agreement in the early 1990s as well. Both agreements were limited in scope. For research on these early agreements, see Bamberger et al. (2004) and Ito and Lee (2007).

${ }^{3}$ These are the mergers for which each merging party made up more than $1 \%$ domestic scheduled-service passenger revenues prior to merging
} 
the East coast), ${ }^{4}$ and a sparse group of ultra low cost carriers (e.g. Spirit, Frontier).

The effect of consolidation on network structure is ambiguous a priori because there are competing forces that determine which routes will be served after consolidation of two airlines. On the one hand, reduced price competition in routes previously serviced by two consolidating airlines should increase profitability in those routes. The increased profitability in these routes could encourage expanded service on connecting routes due to network effects, and may also create opportunities for new entrants. On the other hand, economies of density suggest decreased service, as the new consolidated entity (consolidated either through codesharing or merger) may drop routes that compete with each other. ${ }^{5}$

To investigate the relationship between mergers and network structure, we use three measures of centrality from graph theory: Degree, Closeness, and Betweenness. These three notions of centrality highlight the role of indirect links between airports, a salient characteristic of networks (Jackson, 2008). Specifically, Degree is the fraction of all possible links that are actually served by at least one airline out of an airport, Closeness is the inverse of the average distance (i.e., number of links) from an airport to every other airport, and $B e$ tweenness is the frequency with which an airport is found to be on the shortest path between two other airports. Our focus is on the paths that passengers need to travel through the network to go from one airport to another airport, and our analysis seeks to understand how consolidation has influenced the number and structure of links in those paths, as captured by these three measures of centrality.

We construct the measures of Degree, Closeness, and Betweenness centrality for the national airline network from 1990 to 2015 using the Bureau of Transportation Statistics' T-100 Domestic Segment for U.S. carriers. Then, we run regressions that study the relationship between the three measures and the process of consolidation, through alliances and mergers. Our regressions include a large set of fixed effects to control for unobserved heterogeneity that might affect both the merger decision and decisions that determine the national network

\footnotetext{
${ }^{4}$ Alaska completed its acquisition of Virgin American at the end of 2016.

${ }^{5}$ For more a detailed theoretical treatment of competition and network effects in the airline industry, see Breuckner and Spiller (1991), Hendricks et al. (1997) and Hendricks et al. (1999).
} 
structure.

We find that the domestic industry-wide network has evolved in complex ways. On one hand, each airport services a greater proportion of possible routes (direct links), and is fewer stops away from any given destination. On the other hand, each airport is less frequently found along the shortest route between any two other airports. We interpret these findings as evidence that there are fewer airport that serve as hubs, and each origin airport is more likely to have a direct connection to its potential destination airports. We find that on average, mergers and codeshares are not an important driver of these trends.

Our work is related to the vast literature on the effects of consolidation in the airline industry. The earlier literature on mergers in the airline industry has largely shown that mergers are associated with price increases (Borenstein, 1990; Kim and Singal, 1993; Morrison, 1996; Hergott, 1997; Kwoka and Shumilkina, 2010), though two recent studies find that the effects on prices are mixed (Luo, 2014; Carlton et al., 2016). Richard (2003) took a different approach and provided evidence that mergers were associated with increased flight frequency - thereby suggesting that the overall effect of mergers on welfare is complex and varies by market. Other important contributions used the airline industry to evaluate the performance of merger simulations (Peters, 2006), to illustrate potential cost efficiencies from mergers (White, 1979), and to develop a retrospective analysis on U.S. enforcement actions and merger outcomes (Kwoka, Jr., 2013). There is also a rich literature on the effects of codesharing on prices and traffic of passengers (Bamberger et al., 2004; Armantier and Richard, 2005, 2008; Ito and Lee, 2007; Gayle, 2007, 2008, 2013; Gilo and Simonelli, 2015). Generally, these studies suggest that average prices drop and traffic increases with codesharing, although the prices of the codeshare nonstop tickets increase. Our work is different from these because it focuses on different outcomes, specifically, the Degree, Closeness, and Betweenness centrality measures as variables that summarize the national network structure.

Our work is also related to airline papers that have studied the importance on the direct links (number of spokes) out of an airport as a determinant of demand (Berry, 1990), entry decisions (Berry, 1992; Ciliberto and Tamer, 2009), and market power (Borenstein, 
1989; Ciliberto and Williams, 2010). In contrast, our focus is on the indirect links, as their importance is being captured by the notions of Closeness and Betweenness.

Finally, our work is also related to the empirical literature on network structure as an outcome. Much of this literature studies formation of social networks, for example Jackson and Rogers (2007) and Mayer and Puller (2008). In the context of airlines, Aguirregabiria and Ho (2010) estimate dynamic games of network competition to study entry deterrence in hub-and-spoke networks, while Aguirregabiria and Ho (2012) also estimate a dynamic game of network competition to run policy experiments that show economies of density explain airlines' propensity towards hubbing. Recently, (Yuan, 2016) investigated a model of network competition in the airline industry, where firms can choose the network structure, the capacities, and the prices of nonstop and one-stop connections. These are ambitious and important steps to the understanding of the economics of airline networks, and should be thought of as complementary to our more reduced-form approach to the same questions. ${ }^{6}$

Our paper is organized as follows. In Section 2, we define and illustrate the network measures used in our empirical analysis. In Section 3, we discuss our data source and summarize the network measures. Section 4 describes the development of the airline industry network over the period 1990-2015. Section 5 presents the empirical model used to analyze the effects of mergers and codeshares, and the associated results. Section 6 concludes.

\section{The Economics of Networks in the Airline Industry}

In this section we use examples from the airline industry to introduce notions from graph theory and show how they can be applied to analyze the airline industry. The treatment of these concepts will therefore be very much ad hoc, and we refer the reader to Jackson (2008) for a more detailed and comprehensive discussion.

\footnotetext{
${ }^{6}$ Related literature is largely concerned with characterizing properties of equilibrium networks either when a single agent (usually a firm) controls an entire network, or when individual nodes choose when to form links with other nodes (see Jackson and Wolinsky (1996), Bala and Goyal (2000) and Hendricks et al. (1999)). Another set of literature studies the effects of an existing network structure on agent decisionmaking. For example, Mossel et al. (2015) and citations within their paper study how network structure affects information flow.
} 


\subsection{Basic Notations and Concepts}

An airline network (or graph) consists of airports (nodes) and routes (spokes, links or edges). An airport is denoted by $i=1, \ldots, N$ and the total number of airports is denoted by $N .{ }^{7}$ The network is denoted by a pair $(N, g)$, where $g$ is a real-valued $N \times N$ matrix, whose elements $g_{i k}$ are either 1 or 0 , depending on whether the airline serves the route between airports $i$ and $k$. If $g_{i k}=1$ (or there is a nonstop route between airports $i$ and $k$ ), airports $i$ and $k$ are said to be adjacent. Because we consider a market a nonstop flight in either direction, the airline network is said to be undirected and the matrix $g$ is symmetric. A path between airports $i$ and $k$ in the network $g$ is one sequence of distinct routes that a passenger can take to fly between those two airports. The networks in our analysis are connected networks, meaning that there exists at least one path between any two airports. ${ }^{8}$

A network can also be represented graphically. For example, in Figure 1 we consider the national airline network restricted to the airports of Cleveland (CLE) and Albuquerque (ABQ) and the nonstop routes served from these airports in 2015. In this network, Cleveland and San Diego $(\mathrm{SAN})$ are not adjacent $\left(g_{C L E-S A N}=0\right)$ while Albuquerque and San Diego are $\left(g_{A B Q-S A N}=1\right)$. There are 48 nodes in the network pictured, thus $N=48$.

\section{$2.2 \quad$ Network Measures}

We use three statistics that capture the centrality of an airport in the network of an airline: Degree, Closeness, and Betweenness. As Jackson (2008) points out, the use of multiple summary statistics is helpful to understand the complexity of network structures, as each one of the three measures provides a different perspective. In this paper we study the national network, or what we call the union of all the individual airlines' networks.

We start from the notion of Degree Centrality. The Degree Centrality of airport $i$ in

\footnotetext{
${ }^{7}$ In our analysis we will have a time dimension, which is here omitted for sake of simplicity.

${ }^{8}$ We repeated our analysis treating MSAs as network nodes, rather than airports, by aggregating the network across airports within a metropolitan area. We treat the airports in Washington DC, New York City, Chicago, Dallas, and Houston each as a single node. We find that this has no qualitative effect and a negligible quantitative effect on our results and conclusions. However, we expect if the analysis went beyond just the network structure and examined consumer welfare more directly, there could be interesting differences depending on the substitutability of airports within a MSA.
} 
Figure 1: Network Example: Cleveland and Albuquerque in 2015

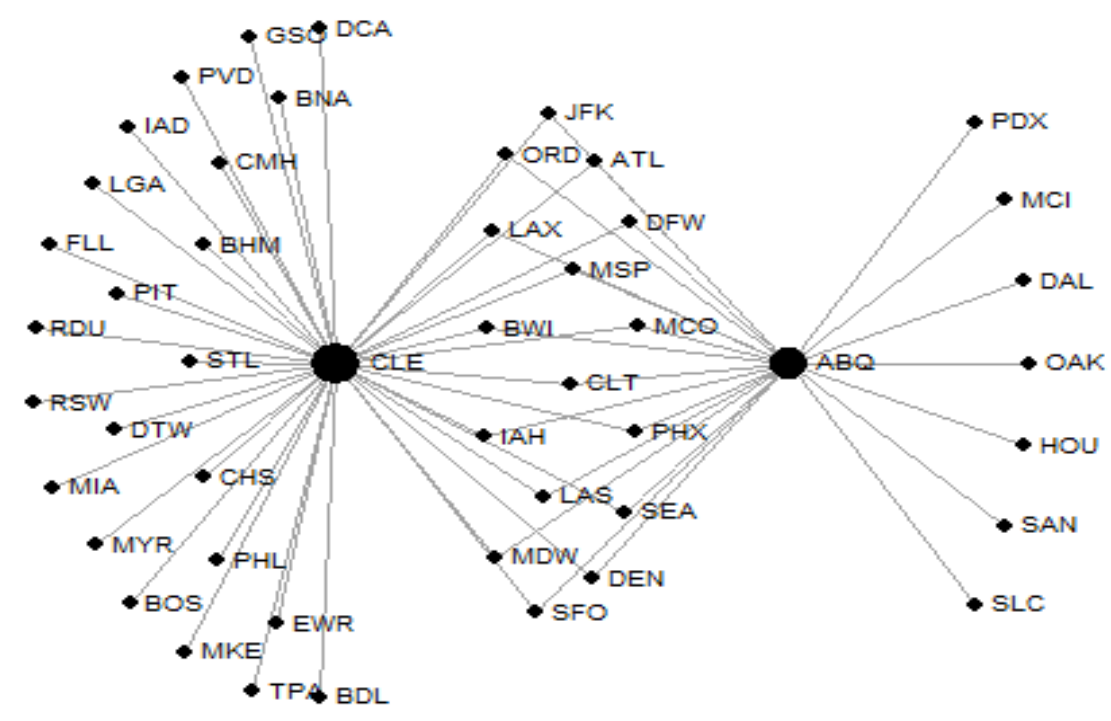

network $g$ can be written as:

$$
d_{i}(g)=\frac{\#\left\{k: g_{i k}=1\right\}}{N-1} .
$$

The numerator is the count of airports that are served out of airport $i$, and the denominator is the number of airports in the network, excluding airport $i$. Thus the Degree Centrality is the proportion of possible connections that are served out of airport $i$. The normalization (division by $N-1$ ) is important when we add a time dimension to our analysis, as the total number of airports in the network will change over time. The normalization ensures that variation in the Degree Centrality over time reflects variation in the density of the network, as opposed to variation in the size of the network.

In Figure 1, the Degree Centrality of San Diego (SAN) is $1 / 47$, or $d_{S A N}(g)=0.021$, the Degree Centrality of Chicago O'Hare (ORD) is $2 / 47$, or $d_{O R D}(g)=0.043$, and the Degree Centrality of Cleveland is $39 / 47$, or $d_{C L E}(g)=0.830$. Therefore, Cleveland is much more 
(Degree) central to this simplified network than are San Diego and Chicago O'Hare.

The measure of Degree Centrality is related to the network measures previously used in the airline literature, and it captures how directly connected an airport is. For example, Berry (1992) uses the number of destinations served out of the airport by an airline as a measure of the network of the airline at that airport, and Ciliberto and Williams (2014) use the measure proposed by Berry (1992) divided by the total number of destinations served by at least one airline out of the airport. Here, the denominator is given by the total number of possible routes that could be served out of the airport, given the total number of airports in the network. Related measures have been used in numerous studies of the airline industry to capture the market presence of a carrier. Of the three measures we consider, the Degree Centrality is the least novel in our analysis because it does not capture the importance of indirect links.

Before formally defining our second centrality measure, Closeness Centrality, we need to introduce an appropriate notion of distance. The shortest path between two airports is called a geodesic path. We denote the number of links in the geodesic path between airports $\mathrm{i}$ and $\mathrm{k}$ by $\ell(i, k)$, and refer to this as the distance between the two airports. Thus, for example, the distance between Pittsburgh (PIT) and Baltimore (BWI) in Figure 1 is $\ell(P I T, B W I)=2$, while the distance between Pittsburgh (PIT) and San Diego (SAN) is $\ell(P I T, S A N)=4$.

The Closeness Centrality can be written as follows:

$$
C_{i}(g)=\frac{(N-1)}{\sum_{k \neq i} \ell(i, k)} .
$$

This measure exploits the distance between nodes and captures the role of connecting flights in the airline network. The denominator is the sum of all shortest distances from airport $i$ to every other airport in the network, and the numerator is the number of other airports. Thus, the Closeness Centrality is the reciprocal of the average shortest distance to every other airport. The connectedness of an entire network can be studied using the average Closeness Centrality of a network. When the average Closeness is low, many nodes will not have a direct connection between them; when the average Closeness Centrality is equal to one, the network is fully connected. While this pattern is also true for Degree Centrality, the 
distinction between Closeness Centrality and Degree Centrality is that Closeness Centrality is affected by the layout of the network (i.e., specifically which direct links are available), while Degree Centrality will be affected only by the number of links relative to the number of potential links.

For the simplified network in Figure 1, the Closeness Centrality of San Diego is 47/140, or $C_{S A N}(g)=0.336$, while $C_{C L E}(g)=0.758$, and $C_{O R D}(g)=0.511$. To illustrate the difference between the Degree and Closeness Centrality measures, we compare the Degree and Closeness of San Diego and Chicago O'Hare to the Degree and Closeness of Cleveland, respectively. The Degree Centrality of San Diego is $2.5 \%$ of the Degree Centrality of Cleveland $\left(\frac{d_{S A N}(g)}{d_{C L E}(g)}=\frac{0.021}{0.830}=0.025\right)$, while the Degree Centrality of Chicago O'Hare is $5.2 \%$ of the Degree Centrality of Cleveland. In contrast, the Closeness Centrality of San Diego was 44.6\% $(0.338 / 0.758)$ of that of Cleveland, while the Closeness Centrality of Chicago O'Hare was $67.4 \%$ of that of Cleveland.

This comparison demonstrates two points. First, both San Diego and Chicago O'Hare seem more "central" when compared to Cleveland by Closeness Centrality than when compared by Degree Centrality. Closeness Centrality captures the fact that in this network, every destination is within fairly close reach from every origin (no geodesic contains more than four distinct links); thus, the Closeness Centrality will be fairly high for every airport. Degree Centrality simply captures the proportion of destinations that can be reached directly from each airport. Using this measure, San Diego and O'Hare pale in comparison to Cleveland. The second point we learn from this comparison is that the Closeness Centrality for Chicago is much higher than that of San Diego, but the Degree Centrality is essentially the same. This captures the fact that Chicago O'Hare is located between two hubs in the middle of the graph, while San Diego is directly adjacent to only one hub at the outskirts of the graph.

The last centrality measure we utilize is Betweenness Centrality, which captures how frequently an airport is found on the shortest path between two other airports. It is calculated as follows: 


$$
B_{i}(g)=\sum_{k \neq l i \notin\{k, l\}} \frac{\frac{P_{i}(k, l)}{P(k, l)}}{(N-1)(N-2)},
$$

where $P_{i}(k, l)$ represents the number of shortest paths between airports $k$ and $l$ with a stop at $i$, and $P(k, l)$ represents the total number of shortest paths between $k$ and $l$. Note that there is not necessarily a unique shortest path: there could be a number of paths of equal length connecting $k$ and $l$ though different airports. If there is a unique shortest path, $\frac{P_{i}(k, l)}{P(k, l)}=1$, but if there are multiple paths tied for shortest, the division by $P(k, l)$ gives equal weight to each path and ensures that the total weight of the pair $k, l$ sums to one. For example, in Figure 1, there are 16 shortest paths that can carry a traveler between San Diego (SAN) to Cleveland (CLE), each one consisting of three links. Thus, each of the 16 shortest paths receives a weight of $1 / 16$ in the calculation of the Betweenness Centrality of ORD, DEN, etc.

The Betweenness Centrality of San Diego is $B_{S A N}(g)=0$, since there are no paths between other airports that go through SAN. Now consider the Betweenness Centrality of Chicago O'Hare (ORD). There are 8 airports to the right of ORD, and 24 to the left. Each pair of these airports has a shortest path through ORD, making the number of shortest paths through ORD equal to $384=2 * 8 * 24 .^{9}$ However, because ORD is one of 16 possible connecting airports on paths of equal length between the 8 on the right and the 24 on the left, divide by 16 to get $384 / 16=24$. Finally, after dividing by the total number of paths that begin and end at airports other than ORD $(48 * 47)$, we get $B_{O R D}(g)=0.01$. A similar calculation reveals that Cleveland is a significant hub in this example, with $B_{C L E}(g)=0.8$.

The three measures described above complement each other to provide a clear picture of the network in Figure 1. While San Diego and Chicago O'Hare only slightly differ in Degree Centrality, their roles in the network are clearly different. Chicago O'Hare is closer to all the other airports than San Antonio is, a difference which is captured by Closeness Centrality. Betweenness Centrality captures hubbing behavior in a way that is not reflected

\footnotetext{
${ }^{9}$ The definition counts each pair of airports twice to account for paths in both directions. If you re-write the formula to count each airport pair once in both the numerator and denominator, you get the same result.
} 
in Closeness Centrality or Degree Centrality. While the Closeness Centrality of Chicago O'Hare and Cleveland are not that different, there is a stark difference in the Betweenness Centrality. The Betweenness measure most strongly reflects Cleveland's function as a hub in this network.

\section{Data}

Our main data source is the Bureau of Transportation Statistics' T-100 Domestic Segment for U.S. carriers. The data contain information on domestic non-stop segment monthly data reported by U.S. carriers. Because we are interested in the overall network, and not in the networks of individual airlines, we look at whether any carrier served a specific route. We further reduce the data by considering only routes between airports that are located in proximity of a Metropolitan Statistical Area in the U.S. ${ }^{10}$ We combine this data with information on each MSA's annual per-capita income and population from the Bureau of Economic Analysis (BEA).

We construct a dataset for our analysis with the airport-month as the unit of observation. There are 190 airports and 53,324 airport-month observations in our dataset. There are on average 174 airports in each year, with some dropped or added to the network over time as service at individual airports starts or ends. For each airport- month we construct the Degree, Closeness, and Betweenness centrality measures as described in Subsection 2.2. ${ }^{11}$ Table 1 reports summary statistics for the original variables, and for the corresponding standardized values that will be used in the empirical analysis.

The variable Degree takes the mean value of 0.121, with substantial variation. Degree has a minimum of 0.006 and a maximum of 0.786. Remember that in the definition of Degree given in equation 1, the denominator is equal to the number of airports belonging to the network in a given year, minus 1 . Thus, the 0.121 also means that on average there were approximately $21(0.121 \times 172)$ routes out of an airport. In other words, $12 \%$ of all

\footnotetext{
${ }^{10}$ We use the U.S. Department of Commerce's 2012 data to identify Metropolitan Statistical Areas in the U.S.

${ }^{11}$ We use the network analysis program prepared by Grund (2015).
} 
possible direct connections are served by any airline at an average airport. To facilitate the interpretation of the results and the comparison across years, we standardize the measure of Degree so that the mean is 0 and the standard deviation is 1 . This variable ranges from -.808 at the minimum to 4.655 at the maximum, which implies that the maximum value is 4.655 standard deviations away from the mean value.

The variable Closeness also exhibits substantial variation, which is clear from its standardized value that varies from -2.827 to 4.289 . Closeness takes the mean value of 0.491 , which means that on average, an airport is approximately $2(1 / .491)$ links away from every other destination in the network.

Finally, we summarize the variable Betweenness in three ways. First, we define the variable IsBetween, which is equal to 1 if an airport is found along the shortest path between at least two other airports in a given month. The mean of IsBetween is equal to 0.655 , which means that 65.5 percent of the airport-month observations are for airports that were between at least two other airports. Second, we define the variable AlwaysBetween, which is equal to 1 if an airport was between at least two other airports for the entire period 1990-2015. The mean of AlwaysBetween is 0.421 , which means that 42.1 percent of the airport-month observations are for airports that have always been between two other airports. Then, we report the summary statistics of the Betweenness Centrality for the whole population, and for the airports for which AlwaysBetween is equal to 1. We see that there is a large variation in both samples, suggesting again substantial heterogeneity in the way that individual airports function within the national network. Finally, we report the standardized value of Betweenness Centrality for the airport for which AlwaysBetween is equal to 1, and we see that the maximum is 8.087, while the minimum is -0.490 .

Next, we report the standardized measures at the top 20 airports ranked from top to bottom. This provides some insight into how the different measures capture different aspects of network connectivity and hubbing. Table 2 provides the rank in the first column followed by the rank-holder airport and the value of the centrality measure for each of the three measures. 
Table 1: Summary Statistics

\begin{tabular}{lccccc}
\hline & Count & Mean & St. Dev. & Min & Max \\
\hline Number of Airports per Year & 26 & 173.538 & 4.292 & 161.000 & 181.000 \\
Degree & 53,324 & 0.121 & 0.143 & 0.006 & 0.786 \\
Standardized Degree & 53,324 & -0.002 & 0.998 & -0.808 & 4.655 \\
Closeness & 53,324 & 0.491 & 0.078 & 0.272 & 0.824 \\
Standardized Closeness & 53,324 & -0.004 & 1.000 & -2.827 & 4.289 \\
IsBetween & 53,324 & 0.655 & 0.476 & 0.000 & 1.000 \\
AlwaysBetween & 53,324 & 0.421 & 0.494 & 0.000 & 1.000 \\
Betweenness & 53,324 & 0.006 & 0.021 & 0.000 & 0.261 \\
Betweenness*1[If AlwaysBetween=1] & 22,464 & 0.015 & 0.030 & 0.000 & 0.261 \\
Standardized Betweenness*1[If AlwaysBetween =1] & 22,464 & 0.001 & 1.002 & -0.490 & 8.087 \\
\hline
\end{tabular}

Note: This table presents summary statistics of variables used in analysis. Statistics are computed for the entire period 1990-2015.

There are several observations that can be made. First, the three variables do a fine job identifying the main hubs, such as Atlanta (Delta Airlines), Chicago O'Hare (American and United), and Dallas Fort-Worth (American). Second, Degree and Closeness provide largely the same information, as far as hubs are concerned, as the rankings in the first columns are identical in the first 18 spots. Third, there are substantial differences between the rankings by Degree and Closeness, versus the rankings by Betweenness (as before, restricted to airports for which AlwaysInBetween is equal to 1), with the exception of the first three spots. The differences are both in the ordinal sequence of the airports, as well in the magnitude of the differences across airports.

The ranking by Betweenness provides a very interesting description of the airline industry, where there are few airports that are clearly hubs of connectivity: Atlanta, Chicago O'Hare, Dallas Fort-Worth, Houston International, Charlotte, and Detroit Wayne. These airports have a Betweenness Centrality that is well over one standard deviation above the mean value. Other airports, such as Las Vegas, Minneapolis/St. Paul, Denver, San Francisco, Pittsburgh have a Betweenness that is $1 / 2$ of a standard deviation away from the mean. Finally, there is third group that has a Betweenness that is less than 1/2 from the mean: St Louis, Los Angeles, Cincinnati, Philadelphia, Seattle, and Newark. Thus, there are really three sets of 
Table 2: Top 20 Airports by Standardized Degree, Closeness, and Betweenness

\begin{tabular}{cll|ll|ll}
\hline Rank & \multicolumn{2}{c}{ Degree } & \multicolumn{2}{c}{ Closeness } & \multicolumn{2}{c}{ Betweenness } \\
\hline 1 & ATL & 3.79 & ATL & 3.31 & ATL & 4.69 \\
2 & ORD & 3.55 & ORD & 3.06 & ORD & 3.23 \\
3 & DFW & 3.16 & DFW & 2.69 & DFW & 2.92 \\
4 & DTW & 2.67 & DTW & 2.28 & IAH & 1.77 \\
5 & IAH & 2.52 & IAH & 2.15 & CLT & 1.45 \\
6 & CLT & 2.49 & CLT & 2.12 & DTW & 1.33 \\
7 & MSP & 2.24 & MSP & 1.93 & LAS & 0.97 \\
8 & DEN & 2.22 & DEN & 1.92 & MSP & 0.85 \\
9 & LAS & 2.04 & LAS & 1.81 & DEN & 0.78 \\
10 & CVG & 2.01 & CVG & 1.78 & SFO & 0.69 \\
11 & EWR & 1.92 & STL & 1.69 & PIT & 0.62 \\
12 & STL & 1.90 & EWR & 1.69 & STL & 0.49 \\
13 & PHL & 1.85 & PHL & 1.64 & LAX & 0.39 \\
14 & MCO & 1.71 & MCO & 1.53 & CVG & 0.30 \\
15 & PHX & 1.65 & PHX & 1.50 & PHL & 0.18 \\
16 & PIT & 1.59 & PIT & 1.48 & SEA & 0.15 \\
17 & LAX & 1.51 & LAX & 1.41 & EWR & 0.05 \\
18 & CLE & 1.50 & CLE & 1.38 & PHX & -0.02 \\
19 & DCA & 1.39 & IAD & 1.32 & MCO & -0.03 \\
20 & IAD & 1.37 & BOS & 1.26 & IAD & -0.04 \\
\hline
\end{tabular}

Note: This table shows the top 20 airports ranked by their average standardized Degree, Closeness, and Betweenness over the entire period 1990-2015.

hubs. In the remainder of the paper, we will investigate how their role has changed over time.

Overall, we learn that the measures of Degree, Closeness, and especially Betweenness, provide consistent and clear measures to identify hubs in the airline industry. ${ }^{12}$ Next, we use these measures to understand how the network structure of the airline industry has changed from 1990 to 2015.

\footnotetext{
${ }^{12}$ See Borenstein (1992) for a comparison of the hubs of the airline industry in the early 1990s, and the ones that the network measures here presented identify.
} 


\section{Twenty-five Years of Airline Networks: The Big Pic- ture}

We now investigate how the network structure of the airline industry overall has developed since 1990. Table 3 summarizes the network measures by year every five years. Just looking at this table, we would conclude that the average Degree and Closeness measures generally increased between 1990 and 2005, then declined moderately since 2005. Betweenness (for airports that have non-zero Betweenness) tends to move opposite the other two measures.

Table 3: Summary Statistics by Year

\begin{tabular}{ccccccc}
\hline Year & Degree & $\begin{array}{c}\text { Standardized } \\
\text { Degree }\end{array}$ & Closeness & $\begin{array}{c}\text { Standardized } \\
\text { Closeness }\end{array}$ & $\begin{array}{c}\text { Betweenness } \\
\text { AlwaysBetween=1 }\end{array}$ & $\begin{array}{c}\text { Standardized } \\
\text { Betweenness } \\
\text { AlwaysBetween=1 }\end{array}$ \\
\hline 1990 & 0.119 & -0.012 & 0.477 & -0.180 & 0.015 & 0.016 \\
1995 & 0.105 & -0.113 & 0.475 & -0.210 & 0.016 & 0.039 \\
2000 & 0.118 & -0.024 & 0.491 & -0.007 & 0.015 & 0.004 \\
2005 & 0.135 & 0.098 & 0.505 & 0.178 & 0.014 & -0.022 \\
2010 & 0.128 & 0.052 & 0.500 & 0.108 & 0.014 & -0.015 \\
2015 & 0.129 & 0.057 & 0.502 & 0.145 & 0.014 & -0.028 \\
\hline
\end{tabular}

Note: This table presents summary statistics of variables used in analysis, by year.

These are simply summary statistics and do not control for any unobservable characteristics of individual airports, which may fall in and out of the network. To address this problem and to control for seasonality, we regress each of the standardized network measures on year, month, and airport fixed effects, and present the year fixed effects in Figure $2 .{ }^{13}$ The figure shows an upward trend in both Degree and Closeness until 2007, confirming the conclusions we reach by looking at Table 3. While the measures decline since 2007, the average Degree and Closeness are higher in 2015 than in 1990, indicating that the network as a whole features relatively more links from the average airport than it did in 1990, and (on average) fewer connections required to travel between any two airports. The average Betweenness among

\footnotetext{
${ }^{13}$ In the Betweenness regression we have included only airports for which Betweenness is non-zero.
} 
airports for which Betweenness is nonzero has decreased. Together, these results imply that the average hub airport is less critical to linking other airports than it was in 1990 — in other words, there are more direct flights and/or more options for connecting routes between any two airports.

Figure 2: Degree, Closeness and Betweenness over Time

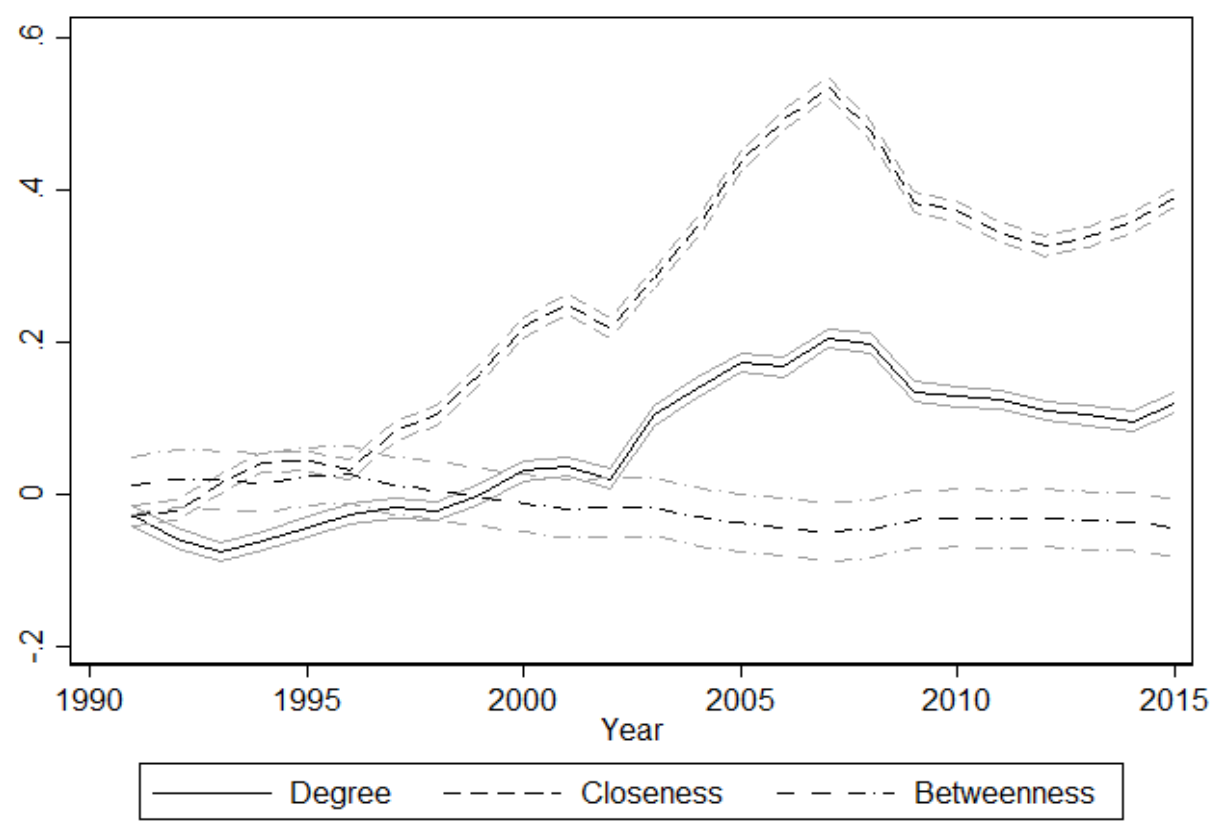

Note: This figure presents the year fixed effects and associated confidence intervals from separate OLS regressions of standardized Degree, Closeness, and Betweenness on a constant along with year, month, and airport fixed effects.

While the average Degree and Closeness have increased and the average Betweenness has decreased over time, these effects are not uniform across airports.

Table 4 shows the average Degree Centrality by airport by year for selected years. A few points are noteworthy here: first, there is substantial variation, second, Degree does give us an indication of hubbing within the national network. For example, we see Chicago O'Hare, Atlanta, and Dallas with relatively large Degree measures. St. Louis (STL), which is in the top 5 airports by degree in 1990, drops off the top 20 by 2010. Cincinnati (CVG) rises to rank 5 in 2000, but is 19th in 2010 and drops off the top 20 in 2015. Pittsburgh (PIT) falls off the top 20 by 2010. Meanwhile, a few airports have gained rank. For example, Las Vegas 
(LAS) is not in the top 20 in 1990 or 2000 , but rises to rank 5 by 2015 .

Table 4: Top 20 Airports by Standardized Degree, by Year

\begin{tabular}{c|ll|ll|ll|ll}
\hline Rank & \multicolumn{2}{c}{1990} & \multicolumn{2}{c}{2000} & \multicolumn{2}{c}{2010} \\
\hline 1 & ORD & 3.64 & ATL & 3.97 & ATL & 3.88 & ATL & 4.13 \\
2 & ATL & 3.07 & ORD & 3.25 & ORD & 3.66 & ORD & 3.98 \\
3 & DFW & 2.88 & DFW & 3.15 & DFW & 3.43 & DFW & 3.56 \\
4 & PIT & 2.35 & IAH & 2.96 & DTW & 3.26 & CLT & 3.44 \\
5 & STL & 2.21 & CVG & 2.77 & LAS & 2.87 & LAS & 2.82 \\
6 & CLT & 2.20 & DTW & 2.63 & CLT & 2.85 & IAH & 2.80 \\
7 & DEN & 1.99 & STL & 2.45 & IAH & 2.84 & DTW & 2.77 \\
8 & DTW & 1.70 & CLE & 2.21 & DEN & 2.60 & DEN & 2.74 \\
9 & MSP & 1.65 & EWR & 2.05 & MSP & 2.53 & MSP & 2.54 \\
10 & IAD & 1.62 & MSP & 2.01 & MCO & 2.27 & PHL & 2.43 \\
11 & IAH & 1.61 & DEN & 1.95 & PHL & 2.20 & DCA & 2.18 \\
12 & BWI & 1.57 & CLT & 1.93 & EWR & 1.95 & EWR & 2.07 \\
13 & PHX & 1.51 & PIT & 1.92 & IAD & 1.95 & IAD & 1.90 \\
14 & CVG & 1.51 & PHX & 1.66 & MEM & 1.93 & LAX & 1.83 \\
15 & EWR & 1.47 & LAS & 1.63 & PHX & 1.83 & MCO & 1.78 \\
16 & MEM & 1.45 & MCO & 1.58 & LAX & 1.76 & BWI & 1.76 \\
17 & LAX & 1.45 & PHL & 1.54 & DCA & 1.75 & PHX & 1.76 \\
18 & SFO & 1.43 & LAX & 1.52 & LGA & 1.74 & MDW & 1.73 \\
19 & PHL & 1.33 & LGA & 1.13 & CVG & 1.66 & LGA & 1.65 \\
20 & LGA & 1.29 & MDW & 1.12 & BWI & 1.62 & BOS & 1.54 \\
\hline
\end{tabular}

Note: This table shows the top 20 airports in selected years, ranked by their average standardized Degree in each year.

Some of these examples have interesting back stories. For example, service at Cincinnati (CVG) suffered substantial cuts between 2006 and 2009 in the midst of Delta's bankruptcy and subsequent merger with Northwest Airlines. At the time of the merger, Delta stated that it did not intend to close any hubs in the merged airline, but years after the merger, we find that the Degree of the Cincinnati airport has declined substantially, suggesting that Delta was unable to follow through on its original intention (Delta News Hub, 2008).

Service at St. Louis Lambert International Airport (STL) was affected by two significant events in 2001: the merger of Trans World Airlines with American Airlines in early 2001, and the terrorist attacks of September 11, 2001, which decreased demand for all airline travel. 
According to some sources, American initially intended to send more traffic through STL after the merger to avoid congestion at its hub in Chicago O'Hare (ORD), but plans changed after September 11, when reduced demand for air travel ended concerns over congestion at ORD (Schoenberger, 2010). ${ }^{14}$

The analysis is very similar for the Closeness Centrality by airport over time. We refer the reader to the appendix for the top 20 airports by Closeness Centrality in selected years.

Table 5 illustrates how Betweenness separates major hubs from non-hubs. By this measure, Chicago O'Hare (ORD) was the most important hub in 1990, but by 2000 Atlanta had overtaken Chicago. By 2010, Cinncinnati and St. Louis had stopped functioning as hubs (as discussed above), and by 2015, Charlotte became a significant hub. Overall, the Table confirms the finding in Figure 2 that Betweenness has decreased.

Notice that the standardized value of Betweenness are more volatile than for the other measures. This is because only the airports with non-zero Betweenness for the entire data period are included, prior to the standardization, and because the Betweenness measure is designed to be quite sensitive to changes throughout the network. ${ }^{15}$

There are two noteworthy changes in Table 5 that deserve mention: first, Cleveland's (CLE) appearance as rank 12 in year 2000 and noticeable absence in the other years, and Atlanta's (ATL) dramatic increase in Betweenness from 1990 to 2000. The movement of CLE is consistent with efforts made by Continental to build its hub capacity at CLE throughout the 1990s, and subsequent challenges in the 2000s. Continental expanded their operation in 1999, so much that in 1999 a new concourse was completed to accommodate the new growth. After 2000, the Sept 11th attacks affected demand for the entire network, so it is likely this demand shock affected Continental's need for the hub in CLE in the early 2000s. The merger of Continental and United in 2010 arguably introduced new incentives for the network structure. In Atlanta, the Betweenness measure jumps substantially between 1990

\footnotetext{
${ }^{14}$ In our regression analysis of the effect of mergers, we leave out the merger of Trans World and American, because it will be impossible to distinguish the effect of this merger from the effect of the September 11th attacks, as the two events occurred within the same year.

${ }^{15}$ Per Table 1, we include approximately 42 percent of the airports when we analyze the Betweenness measure.
} 
Table 5: Top 20 Airports by Standardized Betweenness, by Year

\begin{tabular}{c|lc|lc|lc|ll}
\hline Rank & \multicolumn{2}{c}{1990} & \multicolumn{2}{c}{2000} & \multicolumn{2}{c}{2010} & \multicolumn{2}{c}{2015} \\
\hline 1 & ORD & 4.79 & ATL & 6.39 & ATL & 3.64 & ATL & 3.79 \\
2 & ATL & 3.29 & DFW & 2.99 & ORD & 2.87 & ORD & 3.49 \\
3 & SFO & 2.40 & DTW & 2.52 & DFW & 2.79 & DFW & 3.33 \\
4 & DFW & 2.24 & IAH & 2.45 & LAS & 2.59 & CLT & 2.86 \\
5 & PIT & 2.01 & ORD & 2.17 & IAH & 1.86 & LAS & 1.91 \\
6 & CLT & 1.92 & CVG & 1.25 & DTW & 1.73 & IAH & 1.32 \\
7 & DEN & 0.90 & STL & 0.92 & CLT & 1.62 & DEN & 0.74 \\
8 & MSP & 0.88 & MSP & 0.81 & DEN & 0.77 & DTW & 0.74 \\
9 & IAD & 0.83 & DEN & 0.75 & MSP & 0.71 & MSP & 0.68 \\
10 & STL & 0.70 & LAX & 0.71 & SFO & 0.68 & PHL & 0.52 \\
11 & IAH & 0.66 & PIT & 0.65 & MCO & 0.48 & LAX & 0.52 \\
12 & BWI & 0.59 & CLE & 0.57 & PHL & 0.34 & SEA & 0.20 \\
13 & MEM & 0.44 & SEA & 0.36 & MEM & 0.30 & IAD & 0.17 \\
14 & LAX & 0.41 & CLT & 0.35 & LAX & 0.24 & DCA & 0.05 \\
15 & DTW & 0.20 & EWR & 0.12 & SEA & 0.14 & SFO & 0.03 \\
16 & PHX & 0.17 & MIA & -0.03 & BWI & 0.10 & BOS & 0.02 \\
17 & SEA & 0.08 & SFO & -0.04 & BOS & 0.09 & EWR & 0.00 \\
18 & EWR & -0.05 & LAS & -0.04 & IAD & 0.04 & PHX & -0.00 \\
19 & CVG & -0.09 & MCO & -0.08 & PHX & 0.01 & MCO & -0.11 \\
20 & SLC & -0.15 & PHX & -0.17 & LGA & -0.12 & LGA & -0.16 \\
\hline
\end{tabular}

Note: This table shows the top 20 airports in selected years, ranked by their average standardized Betweenness in each year.

and 2010. This is also consistent with historical anecdotes. In 1990-92 Eastern Airlines ceased operations in Atlanta. In 1993, ValueJet started service out of Atlanta. Meanwhile, Delta expanded operations in Atlanta throughout the 1990s.

Another way to see the change in Betweenness by airport over time is presented in Figure 3 , where the non-standardized values of Betweenness are displayed for all airports. The hubs are clearly distinguished from the rest of the airports in the network, and the patterns over time that we discussed above can also be seen in the Figure.

In this section we have provided more intuition about the network measures, along with examples to show that mergers have affected the network measures at specific airports, such as CVG and STL. From the description of the network as a whole, we have learned 
that national airline network became more connected between 1990 and 2015, with a trend towards more connectedness until approximately 2007, when the trend reversed slightly to bring us to current levels. Connectedness here has three interpretations, corresponding to our three network measures. The analysis of Degree over time shows that the average airport services a greater proportion of possible routes now than in 1990. Similarly, the analysis of Closeness shows that the average origin airport is fewer stops away from any given destination than in 1990, and the analysis of Betweenness shows that the average hub is less frequently found along the shortest route between two other airports than in 1990. In the next section, we analyze the role of mergers and codeshares in the evolution of the airline network over time. 
Figure 3: Betweenness by Airport Over Time

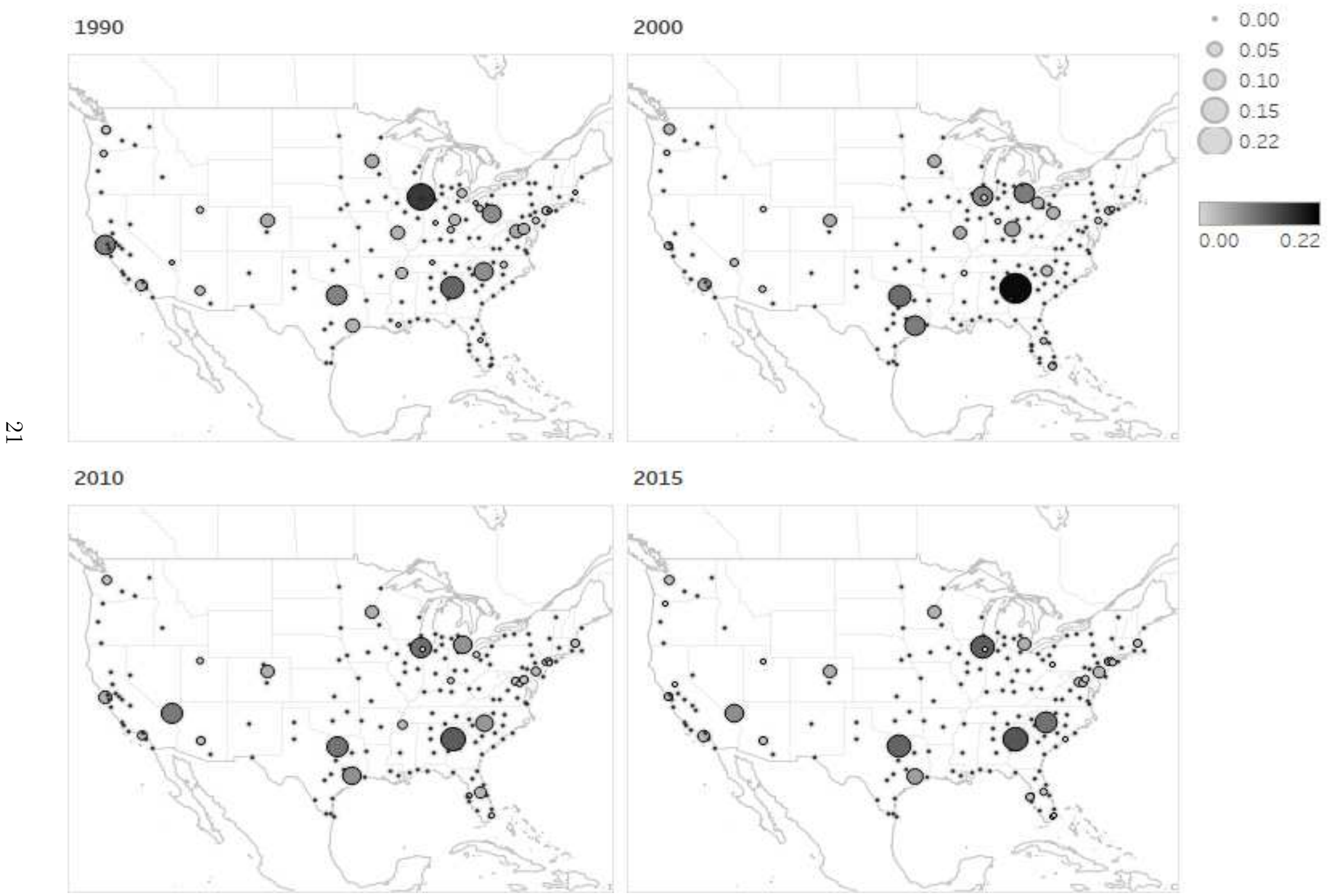

Note: These maps show the average Betweenness (not standardized) by airport by year for years 1990, 2000, 2010, and 2015. Darker color and larger size correspond to airport locations with a higher Betweenness measure in that year. 


\section{The Effect of Mergers on the Network Structure: An Empirical Analysis}

In this section we present an empirical framework to estimate the direction and magnitude of the effect of merger and codeshare agreements on network structure. We present baseline results and several extensions here, and refer the reader to the Appendix for additional specifications.

\section{$5.1 \quad$ Empirical Model}

The airline industry has undergone a notable process of consolidation in recent years. Table 6 lists the five recent mergers studied here, along with the month of announcement, month of completion, and the month the carriers began flying under a single carrier code (the "Single Code Month"). ${ }^{16}$ There have also been many codeshare agreements among major U.S. airlines since 1990. The ones we use in our analysis are listed in Table 7.

For the mergers, we present the results using the merger completion month as the month that the merger occurred. In the Appendix we include tables that show the results with six different specifications of the merger month. We first use the Announcement, Completion, and Single Code months individually, then we have three specifications in which we drop the period of time between Announcement and Completion, between Completion and the Single Code month, and between Announcement and the Single Code month. The results are analogous.

To investigate the average effect across all of the mergers and, separately, of the codesharing agreements, we run the following regression:

$$
\begin{aligned}
Y_{i j, t}= & \alpha+\beta_{1} \text { PostConsolidation }_{j t}+\beta_{2} \text { GDP }_{t}+\beta_{3} \text { JetFuelPrice }_{t} \\
& +\beta_{4} \text { Income }_{i t}+\beta_{5} \text { Population }_{i t}+u_{i j, t}
\end{aligned}
$$

where time (in months) is indexed by $t, i$ indexes the airport, and $j$ indexes the merger or code-sharing agreement. The variable PostConsolidation Po $_{j t}$ is equal to 1 if the observation

\footnotetext{
${ }^{16}$ Note that we exclude the merger of Transworld and American in 2001, because the merger and the terrorist attacks on September 11, 2001 both affected the industry in that year.
} 
Table 6: Airline Mergers Included in Analysis

\begin{tabular}{rrrr}
\hline Announcement & Merger Completed & Single Code & Merging Airlines \\
\hline May, 2005 & Sep, 2005 & Oct, 2007 & America West and US Airways \\
Apr, 2008 & Oct, 2008 & Jan, 2009 & Delta and Northwest \\
May, 2010 & Oct, 2010 & Jan, 2012 & Continental and United \\
Sep, 2010 & Mar, 2011 & Jan, 2015 & AirTran and Southwest \\
Feb, 2013 & Dec, 2013 & Apr, 2015 & American and US Airways \\
\hline
\end{tabular}

Note: This is a list of mergers used in analysis, along with dates of announcement, completion, and the date the carriers began flying under the same carrier code.

Table 7: Codeshare Agreements Included in Analysis

\begin{tabular}{lll}
\hline Month of Codeshare Agreement & End & Airlines Involved \\
\hline October 1994 & May 2002 & CO and HP \\
January 1998 & NW-DL Merger & AS and NW \\
May 1998 & Ongoing & AA and AS \\
January 1999 & CO-DL-NW Codeshare & CO and NW \\
April 1999 & March 2010 & AS and CO \\
January 2003 & March 2014 & US and UA \\
February 2003 & NW-DL Merger & CO, DL, and NW \\
January 2005 & May 2017 & DL and AS \\
October 2009 & CO-UA Merger & CO and UA \\
\hline
\end{tabular}

Note: This is a list of codeshare agreements used in analysis, along with corresponding begin and end months. The last column denotes the airlines involved in the codeshare, where AA is American, AS is Alaska, CO is Continental, DL is Delta, HP is America West, NW is Northwest, UA is United Airlines, and US is US Airways. 
is for a time period after the merger or code-share agreement, and 0 otherwise.

The dependent variable $Y_{i j, t}$ will be one of four different variables: the standardized Degree or Closeness measures, the standardized Betweenness measure for airports that have non-zero Betweenness in all periods, or a dummy variable indicating whether or not the airport has a non-zero Betweenness. In the last case, $\beta_{1}$ can be interpreted as the effect of consolidation on the probability that an airport serves as a link between at least one pair of airports. In all other cases, $\beta_{1}$ will be interpreted as the average effect of consolidation on the network measure.

There are two main concerns for the identification of the causal effect of consolidation on the network measures. First, the effects of consolidation might be confounded by other factors if we consider a time span around the merger or codesharing agreement that is too wide.

We address this concern in two ways. We start by utilizing data from one year before the merger (or codesharing agreement) to one year after the merger, trying to isolate the effect of the merger from other possible factors. ${ }^{17}$ We then repeat the exercise by looking at the data from one year before the merger to three years after the merger, and compare the results with the previous ones, to allow for the possibility that the merger (or codesharing agreement) takes time to be fully implemented. In addition, include controls for aggregate GDP, Jet Fuel Prices, and Population and Income per Capita in the MSA surrounding each airport. These are included to alleviate concern that external cost and demand conditions might drive both the decision to merge and the network changes that occur in the period surrounding the merger. ${ }^{18}$

Our second concern is that the direction of causality could be reversed, whereby the structure of the networks could be what determines why two firms consolidate, rather than

\footnotetext{
${ }^{17}$ We drop the month of the merger, as it is not clear whether this month belongs to the pre- or postperiod.

${ }^{18}$ U.S. Bureau of Economic Analysis, Gross Domestic Product [GDP], retrieved from FRED, Federal Reserve Bank of St. Louis; https://fred.stlouisfed.org/series/GDP, June 11, 2017. JetFuelPrice is the U.S. Gulf Coast Kerosene-Type Jet Fuel price in dollars per gallon from the U.S. Energy Information Administration, retrieved from https://www.eia.gov/dnav/pet/hist/LeafHandler.ashx?n=pet\&s=eer epjk_pf4_rgc_dpg\&f=m.
} 
the other way around. First, we include airport-merger (or airport-codeshare) fixed effects. For example, we will have one dummy variable indicating whether or not the observation comes from DCA during the year before or after the Continental-United merger date, and a separate dummy indicating DCA during the year before or after the American-US Airways merger date. Recall that the airports are the nodes of the network, and the network measures that we use are constructed at the airport level. The airport-merger fixed effects control for any unobserved heterogeneity at the airport level that could have induced two firms to consolidate their operations nationally. For example, if the hub of an airline is at a city that is in economic and population decline (e.g. Trans World Airlines at St. Louis), then the airline at that hub could consider merging with another one that has its hub in cities that are growing (e.g. American at Dallas, Miami, and Chicago). The inclusion of the airport-merger fixed effects means that we will identify the effect of the mergers from the within variation in the network measures at each airport for that merger over one or three years after the merger. Second, we include airport-specific time trends, which are obtained by interacting a trend variable with airport specific fixed effects. The airport-specific trends control for any unobserved heterogeneity that changes over time, such as an historical decline or increase in the demand for travel out of an airport. Thus, while the airport-merger fixed effects control for the average unobserved heterogeneity at the airport level that might induce a merger of two airlines, the airport-specific trends control for long run trends in the unobserved heterogeneity at each airport. We also include fixed effects for quarter of the year to control for the possibility that airlines may serve different routes at different times of year.

This discussion leads to the following specification for the unobservable term:

$$
u_{i j, t}=\epsilon_{i j}+\epsilon_{i} * \text { trend }_{t}+\epsilon_{t}+\epsilon_{i j, t}
$$

where $\epsilon_{i j}$ is the airport-merger fixed effect, $\epsilon_{i} *$ trend $_{t}$ is the airport-specific trend, $\epsilon_{t}$ is the quarter fixed effect, and $\epsilon_{i j, t}$ is an idiosyncratic shock.

One last concern is that an individual merger or code-sharing agreement might be driving the result. For this reason, we also present the results when the regression is estimated separately for each merger and codesharing agreement. In practice, instead of stacking the 
data and measuring time relative to the merger date, we estimate the effect using the data on each merger period separately. We will then have multiple regressions of the following type:

$$
\begin{aligned}
Y_{i, t}= & \alpha+\beta_{1} \text { PostConsolidation }_{t}+\beta_{2} G D P_{t}+\beta_{3} \text { JetFuelPrice }_{t} \\
& +\beta_{4} \text { Income }_{i t}+\beta_{5} \text { Population }_{i t}+u_{i, t},
\end{aligned}
$$

where $u_{i, t}=\epsilon_{i}+\epsilon_{i} * \operatorname{trend}_{t}+\epsilon_{t}+\epsilon_{i, t}$.

\subsection{The Effect of Mergers on Network Structure}

Table 8 presents the estimation results for the regression in Equation 4 . We only present

the results for $\beta_{1}$, and refer the reader to the Appendix for the results for the complete set of parameters.

The estimates for $\beta_{1}$ in equation 4 are all statistically insignificant and small in magnitude. We estimate $\beta_{1}=-0.00493$ for the case when the dependent variable is the Degree Centrality, and $\beta_{1}=-0.0024$ for the case when the dependent variable is the Closeness Centrality. The point estimates imply that the mergers studied here have led to a decline of less than a one percent of a one standard deviation in both centrality measures. These results suggest that mergers have largely not had any meaningful effect on the long term trend of more connectedness that was described in Section 4. The results that mergers have minimal effects on the aggregate network are confirmed by the estimation results when the dependent variable is the standardized Betweenness for airports that have positive Betweenness throughout the data period. We find that the coefficient estimate is -0.00121 , corresponding to a decrease of less than 0.1 percent of a standard deviation. The last row of Table 8 presents the results for a linear probability model where the dependent variable takes the value 0 if Betweenness is equal to 0, and 1 if Betweenness is greater than 0. We see that mergers are associated with a non-statistically significant increase of less than one percent (0.00779) in the probability that an airport serves as a connection along the shortest route between two other airports.

The remaining columns of Table 8 present the results for the mergers separately, as in equation 6 . 
Row 1 of Column 2 shows the effect of the merger on the standardized Degree measure for the merger of US Airways and America West. We find a statistically significant coefficient estimate equal to -0.0389 , or approximately 4 percent of a one standard deviation, which means that in the case of US Airways and America West, the merger decreased the average airport's Degree Centrality. Similarly, the merger of United and Continental also decreased the average airport's Degree centrality by 2 percent (0.0202) of a one standard deviation, although the estimate is only marginally statistically significant. The other mergers (Southwest with AirTran, American with US Airways, and Delta with Northwest) did not have any statistically significant effect on Degree centrality. In Row 2, we find that the only merger that had a significant effect on Closeness was the merger of Delta and Northwest. In this case, average Closeness increased by just under 6 percent of a standard deviation (0.0588). In Row 3 we find no evidence that any individual merger had an effect on Betweenness. In Row 4 we find that the mergers of United with Continental, Delta with Northwest, and American with US Airways increased the probability that an airport acts as a connection between two other airports, respectively by $4.44,7.67$ and 4.24 percentage points.

We now investigate how the results change if we increase the span of the time window. ${ }^{19}$ To do this, we include data on the year before and the third year after each merger. The results are presented in Table 9. Again, the average effects are all statistically insignificant and very small, consistent with the findings in the first column of Table 8.

Columns 2 through 6 show the results for individual mergers. In Row 1, we see that the merger of US Airways and America West is associated with a decrease in Degree of 4 percent (0.0368) of one standard deviation, while the merger of Delta and Northwest is associated with an increase in Degree of 12.9 percent (0.129) of one standard deviation. The remaining three mergers had no statistically significant effect on Degree. These results are broadly consistent with those in Table 8, although the substantially increased coefficient (from a statistically insignificant 0.0209 to a highly significant 0.129 ) for Delta and Northwest suggests that growth in the Degree measure picked up in years two and three after that

\footnotetext{
${ }^{19}$ This is in the same spirit as Morrison (1996), who looks at the effects of mergers 8 and 9 years after they were completed.
} 
merger.

The effects of individual mergers on Closeness can be seen in Row 2. We find significant and positive effects for the mergers of Southwest with AirTran and Delta with Northwest, but a significant negative effect for the merger of American with US Airways. Thus, the average effect of a merger on Closeness (seen in Column 1) is not very meaningful for predicting the long-term effect of any individual merger.

In Row 3, we see that all mergers have statistically insignificant effects on Betweenness in the long term. In Row 4, we find that most mergers have no statistically significant effect on the probability that an airport serves as a connecting airport between two others. There are only marginally significant effects for the mergers of Southwest with Airtran (a decrease of 0.0517 standard deviations) and of Delta with Northwest (and increase of 0.147 standard deviations).

Overall, the results in in Table 9 confirm the conclusion we drew from Table 8: mergers did not have any meaningful effect on the long term trend of more connectedness that was described in Section 4.

\subsection{The Effect of Codeshare Agreements on Network Structure}

In this section we look at codesharing agreements, using the same methodological approach as in the previous section. Like mergers, codeshare agreements present a tradeoff between market power and cost efficiencies that make it difficult a priori to reach a conclusion regarding the effect on existing networks and subsequent entry.

Recall that in the previous subsection, we saw that on average, mergers have no statistically significant effects on any of the centrality measures. In Table 10, we find similar results for codeshares, although codeshares on average have a statistically significant effect at the 10\% level for the Degree and Closeness centrality measures. The first entry in Column 1 suggests that the average effect of a codeshare is to slightly increase the Degree centrality, by about 0.3 percent of a standard deviation. In Row 2 of 10 , we see that the average effect of codeshares on Closeness is about -0.004, or a decrease of 0.4 percent of a standard 
deviation. $^{20}$ The last two rows (first column) suggest that codeshares have no statistically significant effect on Betweenness, either when measured as the standardized Betweenness for airports with non- zero Betweenness, or when coded as a binary variable that indicates whether or not Betweenness is greater than zero.

Looking across Row 1, we see that the average obscures some variation in effects by individual codeshare. The many of the estimated coefficients are not statistically significant, the codeshare agreements of Alaska and Continental, Delta and Alaska, and Continental and United are associated with a statistically significant decrease in Degree - 3.4 percent (0.0344), 14.2 percent $(0.142)$, and 1.8 percent (0.0179) of a standard deviation, respectively. Two codeshare agreements are associated with statistically significant increases in Degree. The codeshare agreement between US Airways and United is associated with an increase in Degree of 12.5 percent (0.125) of one standard deviation, and the agreement between Continental, Delta, and Northwest is associated with an increase of about 2 percent (0.0215) of a standard deviation. We conclude that while the average effect is slightly positive and significant, the sign of the effect of an arbitrary code share agreement is ambiguous, as the effects of actual agreements in the past have gone both directions.

In Row 2, we see that effects of individual mergers on Closeness vary from negative and significant (in the case of Alaska and Continental, Delta and Alaska, and Continental and United) to positive and significant (for the codeshares of US Airways and United, and Continental, Delta and Northwest). We conclude that the effect of codeshare agreements on Closeness centrality is ambiguous.

In Rows 3 and 4, there is only one statistically significant result. The codeshare of Continental and America West is estimated to increase the likelihood of an airport serving as a connection on the shortest route between two other airports by 18.6 percentage points. However, because we find no other significant results for Betweenness, we conclude that in general, the effect of codesharing on hubbing within the aggregate network is indistinguish-

\footnotetext{
${ }^{20}$ So far in our analysis, we have seen Degree and Closeness trend together. This is intuitive, but is not necessarily always the case because - given a fixed number of nodes - average Closeness will reflect both the number and layout of links in a network, while average Degree is affected only by the number of links.
} 
able from zero.

Finally, we see if our conclusions change when we expand the time window after the codeshare is in place. In Table 11, we display the $\beta_{1}$ coefficients for the same regressions as in Table 10, except that we include only data from the year before and the third year after each codeshare. The average effects displayed in Column 1 suggest a positive but small effect on Degree (1.31 percent of a standard deviation), and insignificant effects on Closeness and Betweenness (measured in standard deviations for airports that have positive Betweenness). There is a small but positive effect (4.87 percent of a standard deviation) on the probability of positive Betweenness for all airports). These findings are consistent with the results displayed in Table 10 .

Comparing the results for the individual codeshares to those displayed in Table 10, we see some similar results, although some effects are now significant that were not before, and viceversa. For Degree, we find positive and at least marginally significant results for the codeshare agreements involving American and Alaska, US Airways and United, and Continental, Delta and Northwest. The codeshare of Continental and Northwest is associated with a statistically significant decrease in Degree of 13.5 percent of a standard deviation; when we looked at the smaller time window, the effect was statistically insignificant. The codeshares of Alaska and Continental, Delta and Alaska, Continental and United are no longer associated with a significant effect on Degree, as they were in Table 10. In Row 2, the results for Closeness show that all codeshares except the ones between Continental and America West, American and Alaska, and Continental and Northwest are either statistically insignificant or only marginally significant. Row 3 shows no significant results for Betweenness (for airports with non-zero Betweenness), but in Row 4 we see that the codeshares of Alaska and Continental, US Airways and United, and Continental, Delta, and Northwest are associated with statistically significant increases in the probability that an airport serves as a connection between two others.

Overall, we conclude as before, that the effect of codesharing on the industry network is economically small and often statistically indistinguishable from zero. 


\section{Conclusion}

The U.S. airline industry has undergone a process of consolidation and transformation in the years since 1990. In this paper, we investigate how the network structure of the industry evolved from 1990 to 2015. We use three centrality measures from graph theory to describe the network structure of the industry: Degree, Closeness and Betweenness. Using these measures, we find that the industry network has become more connected, where connectedness has three interpretations: 1) that the average airport services a greater proportion of possible routes, 2) that the average origin airport is fewer stops away from any given destination, and 3) that the average hub is less frequently found along the shortest route between two other airports.

We described how each airport's centrality to the network can be measured by Degree, Closeness and Betweenness, and described how these measures have changed at individual airports over time. Specific examples — such as CVG (Cinncinati), which ceased to behave as a hub in the years following the merger of Delta and Northwest — demonstrate that mergers can affect network centrality of individual airports.

Using a simple empirical framework, we find that the evolution in the national network structure is largely independent of the process of consolidation that has occurred over the same period of time. The average effect of a merger or codeshare on all three centrality measures is statistically insignificant and nearly zero in magnitude in nearly all specifications, and variation in results across individual mergers and codeshare agreements highlights the ambiguity of the estimated effects.

Our results cast some doubt on the ability of mergers to expand overall network connectivity. That mergers could increase network connectivity was an argument made by each of the merging carriers in the past 10 years, and was a factor cited by the DOJ in some of its closing statements explaining why they cleared various mergers. Our conclusions, of course, do not either contradict or support an argument that mergers expand the network connectivity of the two merging parties. Instead, our findings show that the entire industry network was not affected by the mergers. 
There are few limitations of our analysis. First, our analysis focuses on the architecture of networks, and does not capture passenger experience in terms of frequencies, better connections, and so on. Those would be measured by consumer-driven traffic data, not network architecture. One way to address this limitation is to build measures of distance that are weighted by the traffic data along the links Opsahl et al. (2010). We leave this to future work.

Another limitation is that, while we can show that mergers did not lead to expanded connectivity, we cannot say anything on what determined the expanded network connectivity described by Figure 2. One hypothesis is that the demand for air travel has increased and changed over time. We also leave the analysis of this question to future work.

Finally, we find that some codeshare and merger agreements had positive effects on network connectivity, while others had negative effects. We can only speculate here that some codeshares and mergers were indeed driven by network considerations, while others might have been driven by other economic objectives. An interesting line of research could compare the effect on prices and quality of service of these codeshare agreements and mergers, and relate the findings to how they differed with respect to their effect on the network architecture. 
Table 8: Estimates of Merger Effects

\begin{tabular}{|c|c|c|c|c|c|c|}
\hline & Avg. Effect & US \& HP & $\mathrm{UA} \& \mathrm{CO}$ & SW \& FL & DL \& NW & AA \& US \\
\hline \multicolumn{7}{|l|}{ Degree } \\
\hline & -0.00493 & $-0.0389 * * *$ & $-0.0202^{*}$ & 0.00229 & 0.0209 & 0.00986 \\
\hline \multicolumn{7}{|c|}{ Closeness } \\
\hline & -0.00244 & 0.00102 & -0.0158 & -0.000126 & $0.0588^{* *}$ & -0.00779 \\
\hline \multicolumn{7}{|c|}{ Betweenness*1[AlwaysBetween=1] } \\
\hline & -0.00121 & 0.00519 & -0.000528 & -0.00121 & 0.0255 & 0.00439 \\
\hline \multicolumn{7}{|c|}{ IsBetween } \\
\hline & 0.00779 & -0.0251 & $0.0444^{*}$ & 0.00591 & $0.0767^{* *}$ & $0.0424^{* *}$ \\
\hline
\end{tabular}

Note: This table presents the estimated coefficients on the Post-Merger indicator after running the OLS regressions described in the text, using one year of data before and after each merger. The first column is the average effect of all mergers. In this regression, we include fixed effects for each airport-merger combination, along with quarter dummies and controls for GDP (in trillions), jet fuel prices, per capita income (in thousands), population (in one-hundred thousands), and airport-specific monthly trends. All monetary values are adjusted to 2015 dollars. In the remaining columns, the effect of each merger is estimated separately. Controls remain the same, except that we include airport fixed effects instead of airport-merger fixed effects. The headings denote the airlines involved in the relevant merger, where AA is American, CO is Continental, DL is Delta, HP is America West, FL is AirTrain, NW is Northwest, UA is United Airlines, US is US Airways, and SW is Southwest. Significance is denoted by ${ }^{* * *} \mathrm{p}<0.01,{ }^{* *} \mathrm{p}<0.05,{ }^{*} \mathrm{p}<0.1$. 
Table 9: Estimates of Merger Effects 1 Year Before, 3 Years After

\begin{tabular}{|c|c|c|c|c|c|c|}
\hline & Avg. Effect & US \& HP & $\mathrm{UA} \& \mathrm{CO}$ & SW \& FL & DL \& NW & AA \& US \\
\hline \multicolumn{7}{|l|}{ Degree } \\
\hline & $-4.05 e-05$ & $-0.0368^{* * *}$ & 0.0462 & 0.0162 & $0.129^{* * *}$ & -0.0129 \\
\hline \multicolumn{7}{|c|}{ Closeness } \\
\hline & -0.0108 & 0.0158 & 0.0247 & $0.0462^{* * *}$ & $0.348^{* * *}$ & $-0.117^{* *}$ \\
\hline \multicolumn{7}{|c|}{ Betweenness*1[AlwaysBetween=1] } \\
\hline & -0.00931 & -0.0124 & -0.0276 & -0.0151 & 0.000756 & 0.0651 \\
\hline \multicolumn{7}{|c|}{ IsBetween } \\
\hline & -0.0110 & 0.0153 & 0.0192 & $-0.0517^{*}$ & $0.147^{*}$ & -0.0771 \\
\hline
\end{tabular}

Note: This table presents the estimated coefficients on the Post-Merger indicator after running the OLS regressions described in the text, using data from the year before and the third year after each merger. The first column is the average effect of all mergers. In this regression, we include fixed effects for each airport-merger combination, along with quarter dummies and controls for GDP (in trillions), jet fuel prices, per capita income (in thousands), population (in one-hundred thousands), and airport-specific monthly trends. All monetary values are adjusted to 2015 dollars. In the remaining columns, the effect of each merger is estimated separately. Controls remain the same, except that we include airport fixed effects instead of airport-merger fixed effects. The headings denote the airlines involved in the relevant merger, where AA is American, CO is Continental, DL is Delta, HP is America West, FL is AirTrain, NW is Northwest, UA is United Airlines, US is US Airways, and SW is Southwest. Significance is denoted by *** $\mathrm{p}<0.01,{ }^{* *} \mathrm{p}<0.05,{ }^{*} \mathrm{p}<0.1$. 
Table 10: Estimates of Codeshare Effects

\begin{tabular}{|c|c|c|c|c|c|c|c|c|c|c|}
\hline & Avg. Effect & $\mathrm{CO} \& \mathrm{HP}$ & AS \& NW & $\mathrm{AA} \& \mathrm{AS}$ & $\mathrm{CO} \& \mathrm{NW}$ & $\mathrm{AS} \& \mathrm{CO}$ & US \& UA & $\mathrm{CO}, \mathrm{DL} \& \mathrm{NW}$ & DL \& AS & $\mathrm{CO} \& \mathrm{UA}$ \\
\hline \multicolumn{11}{|l|}{ Degree } \\
\hline & $0.00302^{*}$ & -0.00297 & 0.0411 & -0.00733 & -0.0304 & $-0.0344^{* *}$ & $0.125^{* * *}$ & $0.0215^{* * *}$ & $-0.142^{* * *}$ & $-0.0179^{* * *}$ \\
\hline \multicolumn{11}{|c|}{ Closeness } \\
\hline & $-0.00407^{*}$ & 0.00935 & -0.00606 & -0.00751 & -0.203 & $-0.0538 * * *$ & $0.0702^{* * *}$ & $0.0207 * * *$ & $-0.106 * * *$ & $-0.0521^{* * *}$ \\
\hline \multicolumn{11}{|c|}{ Betweenness $* 1[$ AlwaysBetween $=1]$} \\
\hline & 0.000760 & -0.0616 & -0.00247 & 0.00220 & 0.0493 & 0.0282 & 0.0394 & -0.00428 & 0.0715 & 0.0157 \\
\hline \multicolumn{11}{|c|}{ IsBetween } \\
\hline & -0.00227 & $0.186^{* *}$ & 0.114 & 0.00427 & 0.0995 & -0.0556 & 0.0327 & -0.00891 & -0.0750 & 0.0104 \\
\hline
\end{tabular}

Note: This table presents the estimated coefficients on the Post-Codeshare indicator after running the OLS regressions described in the text, using one year of data before and after each codeshare. The first column is the average effect of all codeshares. In this regression, we include fixed effects for each airport-codeshare combination, along with quarter dummies and controls for GDP (in trillions), jet fuel prices, per capita income (in thousands), population (in one-hundred thousands), and airport-specific monthly trends. All monetary values are adjusted to 2015 dollars. In the remaining columns, the effect of each codeshare is estimated separately. Controls remain the same, except that we include airport fixed effects instead of airport-codeshare fixed effects. The headings denote the airlines involved in the relevant codeshare, where AA is American, AS is Alaska, CO is Continental, DL is Delta, HP is America West, NW is Northwest, UA is United Airlines, and US is US Airways. Significance is denoted by $* * * \mathrm{p}<0.01, * * \mathrm{p}<0.05,{ }^{*} \mathrm{p}<0.1$. 
Table 11: Estimates of Codeshare Effects 1 Year Before, 3 Years After

\begin{tabular}{|c|c|c|c|c|c|c|c|c|c|c|}
\hline & Avg. Effect & $\mathrm{CO} \& \mathrm{HP}$ & AS \& NW & AA \& AS & $\mathrm{CO} \& \mathrm{NW}$ & $\mathrm{AS} \& \mathrm{CO}$ & US \& UA & $\mathrm{CO}, \mathrm{DL} \& \mathrm{NW}$ & DL \& AS & $\mathrm{CO} \& \mathrm{UA}$ \\
\hline \multicolumn{11}{|l|}{ Degree } \\
\hline & $0.0131 *$ & 0.105 & -0.128 & $0.0648^{* *}$ & $-0.135^{* *}$ & -0.0674 & $0.389^{* * *}$ & $0.118^{* * *}$ & 0.0302 & -0.00429 \\
\hline \multicolumn{11}{|c|}{ Closeness } \\
\hline & 0.000621 & $-0.419^{* * *}$ & -0.128 & $0.171^{* * *}$ & $-0.322^{* * *}$ & $-0.111^{*}$ & -0.0875 & -0.0149 & -0.0284 & -0.0231 \\
\hline \multicolumn{11}{|c|}{ Betweenness $* 1[$ AlwaysBetween $=1]$} \\
\hline & 0.00216 & 0.247 & 0.0595 & -0.0320 & 0.129 & -0.00122 & 0.188 & -0.0191 & -0.0233 & 0.0375 \\
\hline \multicolumn{11}{|c|}{ IsBetween } \\
\hline & $0.0487 * *$ & -0.530 & -0.0964 & -0.0451 & 0.223 & $0.255^{* *}$ & $0.523^{* * *}$ & $0.171^{* *}$ & -0.0472 & 0.0499 \\
\hline
\end{tabular}

Note: This table presents the estimated coefficients on the Post-Codeshare indicator after running the OLS regressions described in the text, using data from the year before and the third year after each codeshare. The first column is the average effect of all codeshares. In this regression, we include fixed effects for each airport-codeshare combination, along with quarter dummies and controls for GDP (in trillions), jet fuel prices, per capita income (in thousands), population (in one-hundred thousands), and airport-specific monthly trends. All monetary values are adjusted to 2015 dollars. In the remaining columns, the effect of each codeshare is estimated separately. Controls remain the same, except that we include airport fixed effects instead of airport-codeshare fixed effects. The headings denote the airlines involved in the relevant codeshare, where AA is American, AS is Alaska, CO is Continental, DL is Delta, HP is America West, NW is Northwest, UA is United Airlines, and US is US Airways. Significance is denoted by ${ }^{* * *} \mathrm{p}<0.01,{ }^{* *} \mathrm{p}<0.05,{ }^{*} \mathrm{p}<0.1$. 


\section{References}

Aguirregabiria, V. and C. Y. Ho (2010). A dynamic game of airline network competition: Hub-and-spoke networks and entry deterrence. International Journal of Industrial Organization 28(4), 377-382.

Aguirregabiria, V. and C. Y. Ho (2012). A dynamic oligopoly game of the US airline industry: Estimation and policy experiments. Journal of Econometrics 168(1), 156-173.

Armantier, O. and O. Richard (2005). Evidence on Pricing from the Continental Airlines and Northwest Airlines Code-Share Agreement. (March).

Armantier, O. and O. Richard (2008). Domestic airline alliances and consumer welfare. RAND Journal of Economics 39(3), 875-904.

Bala, V. and S. Goyal (2000). A Noncooperative Model of Network Formation. Econometrica $68(5), 1181-1229$.

Bamberger, G. E., D. W. Carlton, and L. R. Neumann (2004). An Empirical Investigation of the Competitive Effects of Domestic Airline Alliances. Journal of Law and Economics $47(1)$, 195-222.

Berry, S. (1990). Airport Presence as Product Differentiation. The American Economic Review 80(2), 394-399.

Berry, S. (1992). Estimation of a Model of Entry in the Airline Industry. Econometrica 60(4), 889-917.

Borenstein, S. (1989). Hubs and High Fares: Dominance and Market Power in the U.S. Airline Industry. The RAND Journal of Economics 20(3), 344-365.

Borenstein, S. (1990). Airline Mergers , Airport Dominance, and Market Power. The American Economic Review 80(2). 
Borenstein, S. (1992). The Evolution of U.S. Airline Competition. Journal of Economic Perspectives 6(2), 45-73.

Breuckner, J. and P. Spiller (1991). Competition and mergers in airline networks. International Journal of Industrial Organization 9(3), 323-342.

Carlton, D., M. Israel, I. Macswain, and E. Orlov (2016). Are Legacy Airline Mergers Proor Anti-Competitive ? Evidence from Recent U . S . Airline Mergers.

Ciliberto, F. and E. Tamer (2009). Market Structure and Multiple Equilibria in Airline Markets. Econometrica 77(6), 1791-1828.

Ciliberto, F. and J. W. Williams (2010). Limited Access to Airport Facilities and Market Power in the Airline Industry. Journal of Law and Economics 53(3), 467-495.

Ciliberto, F. and J. W. Williams (2014). Does Multimarket Contact Facilitate Tacit Collusion? Inference on Conduct Parameters in the Airline Industry. RAND Journal of Economics 45(4), 764-791.

Delta News Hub (2008). Delta and Northwest merge, creating premier global airline.

Gayle, B. P. G. (2013). On the Efficiency of Codeshare Contracts between Airlines: Is Double Marginalization Eliminated? American Economic Journal: Microeconomics 5(4), $244-273$.

Gayle, P. G. (2007). Airline Code-Share Alliances and Their Competitive Effects. Journal of Law and Economics 50(4), 781-819.

Gayle, P. G. (2008). An Empirical Analysis of the Competitive Effects of the Delta / Continental / Northwest Code-Share Alliance. Journal of Law and Economics 51(4), $743-766$.

Gilo, D. and F. Simonelli (2015). The Price-Increasing Effects of Domestic CodeSharing Agreements for Non-Stop Airline Routes. Journal of Competition Law and Economics 11(1), 69-83. 
Grund, T. U. (2015). nwcommands. Network Analysis in Stata.

Hendricks, K., M. Piccione, and G. Tan (1997). Entry and Exit in Hub-Spoke Networks. RAND Journal of Economics 28(2), 291-303.

Hendricks, K., M. Piccione, and G. Tan (1999). Equilibria in networks. Econometrica 67(6), $1407-1434$.

Hergott, M. J. (1997). Airport Concentration and Market Power : An Events Study Approach. Review of Industrial Organization 12(5-6), 793-800.

Ito, H. and D. Lee (2007). Domestic Code Sharing, Alliances, and Airfares in the U.S . Airline Industry. Journal of Law and Economics 50(2).

Jackson, M. O. (2008). Social and Economic Networks. Princeton, NJ: Princeton University Press.

Jackson, M. O. and B. W. Rogers (2007). Meeting Strangers and Friends of Friends : How Random are Social Networks? American Economic Review 97(3), 890-915.

Jackson, M. O. and A. Wolinsky (1996). A Strategic Model of Social and Economic Networks. Journal of Economic Theory 71(1), 44-74.

Kim, E. H. and V. Singal (1993). Mergers and Market Power : Evidence from the Airline Industry. The American Economic Review 83(3), 549-569.

Kwoka, J. and E. Shumilkina (2010). The Price Effect of Eliminating Potential Competition: Evidence from an Airline Merger. The Journal of Industrial Economics 58(4), 767-793.

Kwoka, Jr., J. E. (2013). Does Merger Control Work? A Retrospective on U.S. Enforcement Actions and Merger Outcomes. Antitrust Law Journal 78 (3), 619-650.

Luo, D. (2014). The Price Effects of the Delta / Northwest Airline Merger. Review of Industrial Organization 44(1), 27-48. 
Mayer, A. and S. L. Puller (2008). The old boy (and girl) network: Social network formation on university campuses. Journal of Public Economics 92(1-2), 329-347.

Morrison, S. A. (1996). Airline Mergers: A Longer View. Journal of Transport Economics and Policy $30(3), 237-250$.

Mossel, E., A. Sly, and O. Tamuz (2015). Strategic Learning and the Topology of Social Networks, Volume 83.

Opsahl, T., F. Agneessens, and J. Skvoretz (2010). Node centrality in weighted networks : Generalizing degree and shortest paths. Social Networks 32(3), 245-251.

Peters, C. (2006). Evaluating the Performance of Merger Simulation: Evidence from the U. S. Airline Industry. Journal of Law and Economics 49(2), 627-649.

Richard, O. (2003). Flight frequency and mergers in airline markets. International Journal of Industrial Organization 21(6), 907-922.

Schoenberger, R. (2010). End of TWA hurt hub in St. Louis as American Airlines focused on bigger airports.

White, L. J. (1979). Economies of Scale and the Question of "Natural Monopoly" in the Airline Industry. Journal of Air Law and Commerce 44(3), 545-574.

Yuan, Z. (2016). Network Competition in the Airline Industry : A Framework for Empirical Policy Analysis. 


\section{Appendix}

Table 12: Top 20 Airports by Standardized Closeness, by Year

\begin{tabular}{c|ll|ll|ll|ll}
\hline Rank & \multicolumn{2}{c}{1990} & \multicolumn{2}{c}{2000} & \multicolumn{2}{c}{2010} & \multicolumn{2}{c}{2015} \\
\hline 1 & ORD & 3.16 & ATL & 3.50 & ATL & 3.40 & ATL & 3.64 \\
2 & ATL & 2.62 & ORD & 2.78 & ORD & 3.18 & ORD & 3.48 \\
3 & DFW & 2.42 & DFW & 2.69 & DFW & 2.96 & DFW & 3.05 \\
4 & PIT & 1.99 & IAH & 2.52 & DTW & 2.79 & CLT & 2.94 \\
5 & STL & 1.88 & CVG & 2.40 & LAS & 2.45 & LAS & 2.37 \\
6 & CLT & 1.87 & DTW & 2.25 & CLT & 2.43 & IAH & 2.35 \\
7 & DEN & 1.70 & STL & 2.10 & IAH & 2.42 & DTW & 2.32 \\
8 & DTW & 1.49 & CLE & 1.88 & DEN & 2.22 & DEN & 2.30 \\
9 & MSP & 1.49 & EWR & 1.80 & MSP & 2.17 & MSP & 2.14 \\
10 & IAH & 1.44 & MSP & 1.77 & MCO & 1.96 & PHL & 2.05 \\
11 & PHX & 1.37 & DEN & 1.72 & PHL & 1.91 & DCA & 1.85 \\
12 & IAD & 1.37 & CLT & 1.71 & EWR & 1.73 & EWR & 1.77 \\
13 & EWR & 1.36 & PIT & 1.70 & MEM & 1.70 & IAD & 1.66 \\
14 & CVG & 1.35 & PHX & 1.52 & IAD & 1.69 & LAX & 1.61 \\
15 & LAX & 1.35 & LAS & 1.50 & PHX & 1.64 & PHX & 1.56 \\
16 & SFO & 1.33 & MCO & 1.44 & LAX & 1.59 & MCO & 1.55 \\
17 & MEM & 1.31 & PHL & 1.44 & CVG & 1.52 & BWI & 1.55 \\
18 & PHL & 1.21 & LAX & 1.42 & DCA & 1.50 & BOS & 1.41 \\
19 & BWI & 1.19 & BOS & 1.15 & BWI & 1.47 & TPA & 1.33 \\
20 & BOS & 1.11 & MDW & 1.11 & CLE & 1.41 & SEA & 1.32 \\
\hline
\end{tabular}

Note: This table presents the top 20 airports in 1990, 2000, 2010, and 2015, ranked by their standardized closeness. For each year, the first column is the airport code and the second is the airport's average standardized Closeness within the respective calendar year. 
Table 13: Average Merger Effects: Degree

\begin{tabular}{|c|c|c|c|c|c|c|}
\hline & (1) & $(2)$ & $(3)$ & $(4)$ & $(5)$ & (6) \\
\hline Post Merger & $\begin{array}{c}-0.00933^{* * *} \\
(0.00284)\end{array}$ & $\begin{array}{l}-0.00493 \\
(0.00327)\end{array}$ & $\begin{array}{l}0.0122^{* * *} \\
(0.00284)\end{array}$ & $\begin{array}{c}-0.0166^{* * *} \\
(0.00447)\end{array}$ & $\begin{array}{l}-0.0147^{*} \\
(0.00770)\end{array}$ & $\begin{array}{c}-0.0434^{* * *} \\
(0.00990)\end{array}$ \\
\hline quarter $=2$ & $\begin{array}{l}-0.00169 \\
(0.00184)\end{array}$ & $\begin{array}{c}0.00708^{* * *} \\
(0.00171)\end{array}$ & $\begin{array}{l}-0.00102 \\
(0.00205)\end{array}$ & $\begin{array}{l}-0.00249 \\
(0.00177)\end{array}$ & $\begin{array}{l}-0.000169 \\
(0.00195)\end{array}$ & $\begin{array}{c}-0.00664^{* * *} \\
(0.00192)\end{array}$ \\
\hline quarter $=3$ & $\begin{array}{l}-0.00349 \\
(0.00259)\end{array}$ & $\begin{array}{c}0.00692^{* * *} \\
(0.00249)\end{array}$ & $\begin{array}{c}-0.00799^{* *} \\
(0.00312)\end{array}$ & $\begin{array}{c}-0.00425^{*} \\
(0.00244)\end{array}$ & $\begin{array}{l}-0.00537^{*} \\
(0.00324)\end{array}$ & $\begin{array}{c}-0.00969^{* * *} \\
(0.00296)\end{array}$ \\
\hline quarter $=4$ & $\begin{array}{c}-0.0117^{* * *} \\
(0.00269)\end{array}$ & $\begin{array}{c}0.00187 \\
(0.00241)\end{array}$ & $\begin{array}{c}-0.0160 * * * \\
(0.00287)\end{array}$ & $\begin{array}{c}-0.00784^{* * *} \\
(0.00249)\end{array}$ & $\begin{array}{c}-0.0119 * * * \\
(0.00338)\end{array}$ & $\begin{array}{c}-0.0182^{* * *} \\
(0.00320)\end{array}$ \\
\hline GDP & $\begin{array}{c}0.0304^{* * * *} \\
(0.00686)\end{array}$ & $\begin{array}{l}-0.00777 \\
(0.00680)\end{array}$ & $\begin{array}{c}0.0608^{* * * *} \\
(0.00810)\end{array}$ & $\begin{array}{c}0.0257 * * * \\
(0.00732)\end{array}$ & $\begin{array}{c}0.0402^{* * * *} \\
(0.00777)\end{array}$ & $\begin{array}{c}0.0561 * * * \\
(0.00776)\end{array}$ \\
\hline Jet Fuel Price Dollars per Gal & $\begin{array}{c}0.0204^{* * *} \\
(0.00258)\end{array}$ & $\begin{array}{c}0.0127^{* * * *} \\
(0.00260)\end{array}$ & $\begin{array}{c}0.00979 * * * \\
(0.00254)\end{array}$ & $\begin{array}{c}0.0275^{* * * *} \\
(0.00310)\end{array}$ & $\begin{array}{c}0.00228 \\
(0.00265)\end{array}$ & $\begin{array}{c}0.00405 \\
(0.00332)\end{array}$ \\
\hline Per Capita Income $(\$ 1,000 \mathrm{~s})$ & $\begin{array}{l}-0.000921 \\
(0.00152)\end{array}$ & $\begin{array}{c}-0.00327^{* *} \\
(0.00166)\end{array}$ & $\begin{array}{l}-0.00299^{*} \\
(0.00160)\end{array}$ & $\begin{array}{l}0.000802 \\
(0.00175)\end{array}$ & $\begin{array}{c}0.00579 * * * \\
(0.00183)\end{array}$ & $\begin{array}{c}0.00868^{* * *} \\
(0.00226)\end{array}$ \\
\hline Population $(100,000 \mathrm{~s})$ & $\begin{array}{l}-0.0125^{*} \\
(0.00682)\end{array}$ & $\begin{array}{c}-0.0123 \\
(0.00816)\end{array}$ & $\begin{array}{l}-0.00506 \\
(0.00731)\end{array}$ & $\begin{array}{c}-0.0237^{* * *} \\
(0.00910)\end{array}$ & $\begin{array}{c}-0.0113 \\
(0.00985)\end{array}$ & $\begin{array}{l}-0.0172 \\
(0.0111)\end{array}$ \\
\hline Constant & $\begin{array}{l}-0.169 \\
(0.195)\end{array}$ & $\begin{array}{c}0.553^{* *} \\
(0.223)\end{array}$ & $\begin{array}{c}-0.742^{* * *} \\
(0.208)\end{array}$ & $\begin{array}{l}0.0387 \\
(0.232)\end{array}$ & $\begin{array}{c}-0.595^{* *} \\
(0.283)\end{array}$ & $\begin{array}{c}-0.850^{* * *} \\
(0.314)\end{array}$ \\
\hline Observations & 19,707 & 19,728 & 19,208 & 19,731 & 19,160 & 19,163 \\
\hline R-squared & 0.490 & 0.523 & 0.543 & 0.595 & 0.741 & 0.771 \\
\hline Number of panelid & 865 & 865 & 866 & 867 & 864 & 866 \\
\hline Merger Date & $\mathrm{A}$ & $\mathrm{C}$ & $\mathrm{SC}$ & A to $\mathrm{C}$ & $\mathrm{C}$ to $\mathrm{SC}$ & A to $\mathrm{SC}$ \\
\hline
\end{tabular}

Note: This table presents the estimated coefficients on the Post-Merger indicator after running the OLS regressions described in the text with standardized Degree as the outcome variable, using one year of data before and after each merger, and all five mergers together. In this regression, we include fixed effects for each airport-merger combination, along with quarter dummies and controls for GDP (in trillions), jet fuel prices, per capita income (in thousands), population (in one-hundred thousands), and airport-specific monthly trends. All monetary values are adjusted to 2015 dollars. The fixed effects and airport-specific trends are not displayed. Each column presents the results using a different definition of the merger date: "A" is the annoucement date, "C" is the completion date, and "SC" is the single code date. In the last three columns, the time between the noted dates is dropped. Significance is denoted by ${ }^{* * *} \mathrm{p}<0.01,{ }^{* *} \mathrm{p}<0.05,{ }^{*} \mathrm{p}<0.1$. 
Table 14: Average Merger Effects: Closeness

\begin{tabular}{lcccccc}
\hline & $(1)$ & $(2)$ & $(3)$ & $(4)$ & $(5)$ & $(6)$ \\
& & & & & & \\
\hline Post Merger & -0.00515 & -0.00244 & $0.0145^{* * *}$ & -0.00907 & $-0.0291^{* * *}$ & $-0.0450^{* * *}$ \\
& $(0.00395)$ & $(0.00415)$ & $(0.00464)$ & $(0.00552)$ & $(0.00949)$ & $(0.0121)$ \\
quarter $=2$ & -0.00401 & $0.0123^{* * *}$ & 0.000724 & -0.00255 & 0.000966 & $-0.0115^{* * *}$ \\
& $(0.00266)$ & $(0.00293)$ & $(0.00309)$ & $(0.00238)$ & $(0.00312)$ & $(0.00279)$ \\
quarter $=3$ & -0.000808 & $0.0165 * * *$ & -0.00151 & 0.000821 & -0.00443 & $-0.00976^{* *}$ \\
& $(0.00358)$ & $(0.00379)$ & $(0.00468)$ & $(0.00320)$ & $(0.00471)$ & $(0.00410)$ \\
quarter $=4$ & $-0.0190^{* * *}$ & 0.00211 & $-0.0219^{* * *}$ & $-0.0180^{* * *}$ & $-0.0200^{* * *}$ & $-0.0291^{* * *}$ \\
& $(0.00365)$ & $(0.00383)$ & $(0.00446)$ & $(0.00316)$ & $(0.00484)$ & $(0.00439)$ \\
GDP & $0.0793^{* * *}$ & $0.0235^{* *}$ & $0.120^{* * *}$ & $0.0936^{* * *}$ & $0.0957^{* * *}$ & $0.125^{* * *}$ \\
& $(0.00965)$ & $(0.00985)$ & $(0.0119)$ & $(0.00959)$ & $(0.0118)$ & $(0.0116)$ \\
Jet Fuel Price Dollars per Gal & $0.0141^{* * *}$ & 0.00321 & 0.00194 & $0.0306^{* * *}$ & $-0.0127^{* * *}$ & -0.00273 \\
& $(0.00287)$ & $(0.00310)$ & $(0.00303)$ & $(0.00396)$ & $(0.00321)$ & $(0.00410)$ \\
Per Capita Income (\$1,000s) & -0.00240 & $-0.00603^{* * *}$ & $-0.00926^{* * *}$ & 0.00127 & 0.00275 & $0.00745^{* * *}$ \\
& $(0.00187)$ & $(0.00209)$ & $(0.00226)$ & $(0.00192)$ & $(0.00224)$ & $(0.00256)$ \\
Population (100,000s) & -0.00825 & -0.00513 & -0.00101 & -0.0124 & -0.00734 & -0.0112 \\
Constant & $(0.00728)$ & $(0.00853)$ & $(0.00843)$ & $(0.00887)$ & $(0.0103)$ & $(0.0127)$ \\
& $-0.898^{* * *}$ & 0.108 & $-1.436^{* * *}$ & $-1.248^{* * *}$ & $-1.339^{* * *}$ & $-1.949^{* * *}$ \\
& $(0.240)$ & $(0.259)$ & $(0.256)$ & $(0.268)$ & $(0.313)$ & $(0.335)$ \\
Observations & & & & & & \\
R-squared & 19,707 & 19,728 & 19,208 & 19,731 & 19,160 & 19,163 \\
Number of panelid & 0.483 & 0.490 & 0.442 & 0.567 & 0.636 & 0.680 \\
Merger Date & 865 & 865 & 866 & 867 & 864 & 866 \\
\hline
\end{tabular}

Note: This table presents the estimated coefficients from the OLS regressions described in the text with standardized Closeness as the outcome variable, using one year of data before and after each merger, and all five mergers together. In this regression, we include fixed effects for each airport-merger combination, along with quarter dummies and controls for GDP (in trillions), jet fuel prices, per capita income (in thousands), population (in one-hundred thousands), and airport-specific monthly trends. All monetary values are adjusted to 2015 dollars. The fixed effects and airport-specific trends are not displayed. Each column presents the results using a different definition of the merger date: "A" is the annoucement date, "C" is the completion date, and "SC" is the single code date. In the last three columns, the time between the noted dates is dropped. Significance is denoted by ${ }^{* * *} \mathrm{p}<0.01,{ }^{* *} \mathrm{p}<0.05,{ }^{*} \mathrm{p}<0.1$. 
Table 15: Average Merger Effects: Betweenness*1[AlwaysBetween=1]

\begin{tabular}{|c|c|c|c|c|c|c|}
\hline & (1) & $(2)$ & (3) & (4) & (5) & (6) \\
\hline \multirow[t]{2}{*}{ Post Merger } & 0.00239 & -0.00121 & -0.000982 & 0.00165 & -0.00516 & -0.000476 \\
\hline & $(0.00515)$ & $(0.00619)$ & $(0.00602)$ & $(0.00921)$ & $(0.0173)$ & $(0.0218)$ \\
\hline \multirow[t]{2}{*}{ quarter $=2$} & 0.000297 & -0.00201 & -0.000255 & 0.000376 & 0.00144 & 0.00295 \\
\hline & $(0.00313)$ & $(0.00314)$ & $(0.00356)$ & $(0.00317)$ & $(0.00425)$ & $(0.00406)$ \\
\hline \multirow[t]{2}{*}{ quarter $=3$} & -0.000738 & -0.00350 & -0.000594 & -0.000576 & 0.00130 & 0.00207 \\
\hline & $(0.00454)$ & $(0.00470)$ & $(0.00570)$ & $(0.00455)$ & $(0.00695)$ & $(0.00640)$ \\
\hline \multirow[t]{2}{*}{ quarter $=4$} & 0.00127 & -0.00154 & 0.00165 & 0.000981 & 0.00431 & 0.00494 \\
\hline & $(0.00493)$ & $(0.00539)$ & $(0.00611)$ & $(0.00562)$ & $(0.00828)$ & $(0.00733)$ \\
\hline \multirow[t]{2}{*}{ GDP } & -0.00272 & -0.00101 & -0.0193 & -0.00748 & -0.0189 & -0.0184 \\
\hline & $(0.0144)$ & $(0.0147)$ & $(0.0187)$ & $(0.0179)$ & $(0.0202)$ & $(0.0194)$ \\
\hline \multirow[t]{2}{*}{ Jet Fuel Price Dollars per Gal } & -0.00361 & -0.00128 & $2.90 \mathrm{e}-05$ & -0.00467 & -0.00210 & -0.00217 \\
\hline & $(0.00661)$ & $(0.00588)$ & $(0.00581)$ & $(0.00646)$ & $(0.00675)$ & $(0.00786)$ \\
\hline \multirow[t]{2}{*}{ Per Capita Income $(\$ 1,000 \mathrm{~s})$} & 0.00236 & 0.00150 & 0.00160 & -0.000364 & 0.00414 & 0.00182 \\
\hline & $(0.00290)$ & $(0.00308)$ & $(0.00290)$ & $(0.00260)$ & $(0.00375)$ & $(0.00387)$ \\
\hline \multirow[t]{2}{*}{ Population $(100,000 \mathrm{~s})$} & 0.00446 & -0.00214 & -0.00769 & 0.00300 & -0.00140 & 0.00509 \\
\hline & $(0.00560)$ & $(0.00634)$ & $(0.0107)$ & $(0.00557)$ & $(0.0118)$ & $(0.0131)$ \\
\hline \multirow[t]{2}{*}{ Constant } & -0.246 & 0.0117 & 0.519 & 0.0173 & 0.152 & 0.00624 \\
\hline & $(0.352)$ & $(0.366)$ & $(0.604)$ & $(0.397)$ & $(0.638)$ & $(0.684)$ \\
\hline Observations & 8,280 & 8,280 & 8,064 & 8,280 & 8,064 & 8,064 \\
\hline R-squared & 0.628 & 0.611 & 0.553 & 0.711 & 0.740 & 0.782 \\
\hline Number of panelid & 360 & 360 & 360 & 360 & 360 & 360 \\
\hline Merger Date & $\mathrm{A}$ & $\mathrm{C}$ & $\mathrm{SC}$ & A to $\mathrm{C}$ & $\mathrm{C}$ to $\mathrm{SC}$ & A to $\mathrm{SC}$ \\
\hline
\end{tabular}

Note: This table presents the estimated coefficients from the OLS regressions described in the text with standardized Betweenness (for airports with non-zero betweenness) as the outcome variable, using one year of data before and after each merger, and all five mergers together. In this regression, we include fixed effects for each airport-merger combination, along with quarter dummies and controls for GDP (in trillions), jet fuel prices, per capita income (in thousands), population (in one-hundred thousands), and airport-specific monthly trends. All monetary values are adjusted to 2015 dollars. The fixed effects and airport-specific trends are not displayed. Each column presents the results using a different definition of the merger date: "A" is the annoucement date, "C" is the completion date, and "SC" is the single code date. In the last three columns, the time between the noted dates is dropped. Significance is denoted by ${ }^{* * *} \mathrm{p}<0.01,{ }^{* *} \mathrm{p}<0.05,{ }^{*} \mathrm{p}<0.1$. 
Table 16: Average Merger Effects: IsBetween

\begin{tabular}{|c|c|c|c|c|c|c|}
\hline & (1) & $(2)$ & (3) & (4) & $(5)$ & (6) \\
\hline \multirow[t]{2}{*}{ Post Merger } & -0.00727 & 0.00779 & -0.00526 & 0.00214 & 0.0271 & 0.0262 \\
\hline & $(0.00490)$ & $(0.00620)$ & $(0.00654)$ & $(0.00899)$ & $(0.0184)$ & $(0.0202)$ \\
\hline \multirow[t]{2}{*}{ quarter $=2$} & 0.00281 & 0.00440 & -0.00158 & 0.00537 & $1.74 \mathrm{e}-05$ & 0.00217 \\
\hline & $(0.00342)$ & $(0.00345)$ & $(0.00353)$ & $(0.00329)$ & $(0.00380)$ & $(0.00341)$ \\
\hline \multirow[t]{2}{*}{ quarter $=3$} & $-0.00821^{*}$ & -0.00375 & $-0.0155^{* *}$ & $-8.82 \mathrm{e}-05$ & -0.00738 & -0.00215 \\
\hline & $(0.00477)$ & $(0.00555)$ & $(0.00659)$ & $(0.00512)$ & $(0.00650)$ & $(0.00565)$ \\
\hline \multirow[t]{2}{*}{ quarter $=4$} & 0.000741 & 0.00664 & $-0.0134^{*}$ & 0.00627 & 0.00661 & 0.00624 \\
\hline & $(0.00493)$ & $(0.00622)$ & $(0.00715)$ & $(0.00563)$ & $(0.00784)$ & $(0.00689)$ \\
\hline \multirow[t]{2}{*}{ GDP } & $-0.0260 * *$ & $-0.0411^{* *}$ & 0.00217 & $-0.0411^{* * *}$ & $-0.0323^{* *}$ & $-0.0285^{* *}$ \\
\hline & $(0.0131)$ & $(0.0165)$ & $(0.0143)$ & $(0.0156)$ & $(0.0143)$ & $(0.0140)$ \\
\hline \multirow[t]{2}{*}{ Jet Fuel Price Dollars per Gal } & $8.08 \mathrm{e}-05$ & 0.00299 & -0.00352 & 0.00263 & 0.00630 & 0.00363 \\
\hline & $(0.00327)$ & $(0.00327)$ & $(0.00421)$ & $(0.00540)$ & $(0.00451)$ & $(0.00582)$ \\
\hline \multirow[t]{2}{*}{ Per Capita Income $(\$ 1,000 \mathrm{~s})$} & -0.000647 & 0.000729 & -0.000771 & -0.000971 & 0.000918 & 0.00256 \\
\hline & $(0.00249)$ & $(0.00228)$ & $(0.00309)$ & $(0.00230)$ & $(0.00232)$ & $(0.00309)$ \\
\hline \multirow[t]{2}{*}{ Population $(100,000 s)$} & $-0.0112^{* *}$ & $-0.0123^{* *}$ & $-0.0223^{* * *}$ & -0.00822 & $-0.0114^{*}$ & -0.00488 \\
\hline & $(0.00564)$ & $(0.00546)$ & $(0.00795)$ & $(0.00536)$ & $(0.00632)$ & $(0.00655)$ \\
\hline \multirow[t]{2}{*}{ Constant } & $1.347^{* * *}$ & $1.542^{* * *}$ & $1.149^{* * *}$ & $1.533^{* * *}$ & $1.368^{* * *}$ & $1.111^{* * *}$ \\
\hline & $(0.327)$ & $(0.352)$ & $(0.277)$ & $(0.325)$ & $(0.266)$ & $(0.266)$ \\
\hline Observations & 19,707 & 19,728 & 19,208 & 19,731 & 19,160 & 19,163 \\
\hline R-squared & 0.324 & 0.284 & 0.220 & 0.360 & 0.344 & 0.395 \\
\hline Number of panelid & 865 & 865 & 866 & 867 & 864 & 866 \\
\hline Merger Date & $\mathrm{A}$ & $\mathrm{C}$ & $\mathrm{SC}$ & A to $\mathrm{C}$ & $\mathrm{C}$ to $\mathrm{SC}$ & A to $\mathrm{SC}$ \\
\hline
\end{tabular}

Note: This table presents the estimated coefficients from the OLS regressions described in the text with an indicator for non-zero betweenness as the outcome variable, using one year of data before and after each merger, and all five mergers together. In this regression, we include fixed effects for each airport-merger combination, along with quarter dummies and controls for GDP (in trillions), jet fuel prices, per capita income (in thousands), population (in one-hundred thousands), and airport-specific monthly trends. All monetary values are adjusted to 2015 dollars. The fixed effects and airport-specific trends are not displayed. Each column presents the results using a different definition of the merger date: "A" is the annoucement date, "C" is the completion date, and "SC" is the single code date. In the last three columns, the time between the noted dates is dropped. Significance is denoted by $* * * \mathrm{p}<0.01, * * \mathrm{p}<0.05, * \mathrm{p}<0.1$. 
Table 17: Average Codeshare Effects: All Outcomes

\begin{tabular}{|c|c|c|c|c|}
\hline & $\begin{array}{c}(1) \\
\text { Degree }\end{array}$ & $\begin{array}{c}(2) \\
\text { Closeness } \\
\end{array}$ & $\begin{array}{c}(3) \\
\text { Betweenness*1[AlwaysBetween=1] }\end{array}$ & $\begin{array}{c}(4) \\
\text { IsBetween } \\
\end{array}$ \\
\hline Post Codeshare & $\begin{array}{l}0.00302^{*} \\
(0.00168)\end{array}$ & $\begin{array}{r}-0.00407^{*} \\
(0.00233)\end{array}$ & $\begin{array}{l}0.000760 \\
(0.00513)\end{array}$ & $\begin{array}{l}-0.00227 \\
(0.00509)\end{array}$ \\
\hline quarter $=2$ & $\begin{array}{c}0.00309^{* * *} \\
(0.00110)\end{array}$ & $\begin{array}{c}0.00691^{* * *} \\
(0.00146)\end{array}$ & $\begin{array}{l}-0.00347 \\
(0.00384)\end{array}$ & $\begin{array}{c}0.00959 * * * \\
(0.00319)\end{array}$ \\
\hline quarter $=3$ & $\begin{array}{c}0.00258 \\
(0.00183)\end{array}$ & $\begin{array}{c}0.0113^{* * *} \\
(0.00249)\end{array}$ & $\begin{array}{l}-0.00641 \\
(0.00605)\end{array}$ & $\begin{array}{l}0.00925^{*} \\
(0.00532)\end{array}$ \\
\hline quarter $=4$ & $\begin{array}{c}0.00991^{* * *} \\
(0.00324)\end{array}$ & $\begin{array}{c}0.00971^{* * *} \\
(0.00355)\end{array}$ & $\begin{array}{c}-0.00455 \\
(0.0129)\end{array}$ & $\begin{array}{l}0.0149^{* *} \\
(0.00682)\end{array}$ \\
\hline GDP & $\begin{array}{c}-0.0470 * * * \\
(0.0105)\end{array}$ & $\begin{array}{c}-0.0218^{* *} \\
(0.0111)\end{array}$ & $\begin{array}{l}-0.0115 \\
(0.0422)\end{array}$ & $\begin{array}{c}-0.0805^{* * *} \\
(0.0225)\end{array}$ \\
\hline Jet Fuel Price Dollars per Gal & $\begin{array}{c}0.00413 \\
(0.00296)\end{array}$ & $\begin{array}{c}0.00525 \\
(0.00440)\end{array}$ & $\begin{array}{r}-0.000170 \\
(0.00795)\end{array}$ & $\begin{array}{l}-0.00433 \\
(0.00811)\end{array}$ \\
\hline Per Capita Income $(\$ 1,000 \mathrm{~s})$ & $\begin{array}{r}-0.000450 \\
(0.00116)\end{array}$ & $\begin{array}{c}-0.00668^{* * *} \\
(0.00142)\end{array}$ & $\begin{array}{c}0.00220 \\
(0.00256)\end{array}$ & $\begin{array}{l}0.00482^{*} \\
(0.00250)\end{array}$ \\
\hline Population $(100,000 \mathrm{~s})$ & $\begin{array}{c}0.00784 \\
(0.00534)\end{array}$ & $\begin{array}{c}0.0122^{* *} \\
(0.00494)\end{array}$ & $\begin{array}{c}-0.0262^{* *} \\
(0.0129)\end{array}$ & $\begin{array}{c}-0.0107 \\
(0.00870)\end{array}$ \\
\hline Constant & $\begin{array}{c}0.514^{* * *} \\
(0.162)\end{array}$ & $\begin{array}{l}0.325^{*} \\
(0.166)\end{array}$ & $\begin{array}{l}0.981^{*} \\
(0.577)\end{array}$ & $\begin{array}{c}1.785^{* * *} \\
(0.343)\end{array}$ \\
\hline Observations & 35,837 & 35,837 & 15,552 & 35,837 \\
\hline R-squared & 0.582 & 0.536 & 0.543 & 0.325 \\
\hline Number of panelid & 1,523 & 1,523 & 648 & 1,523 \\
\hline
\end{tabular}

Note: This table presents the estimated coefficients from the OLS regressions described in the text, using one year of data before and after each codeshare. In this regression, we include fixed effects for each airport-codeshare combination, along with quarter dummies and controls for GDP (in trillions), jet fuel prices, per capita income (in thousands), population (in one-hundred thousands), and airport-specific monthly trends. All monetary values are adjusted to 2015 dollars. The fixed effects and airport-specific trends are not displayed. Each column presents the results using a different outcome variable, noted in the column header. Significance is denoted by ${ }^{* * *} \mathrm{p}<0.01,{ }^{* *} \mathrm{p}<0.05,{ }^{*} \mathrm{p}<0.1$. 